\title{
ESTUDIO COMPARATIVO DE PLANTAS MEDICINALES VINCULADAS A TRADICIONES INDÍGENAS Y EUROPEAS EN URUGUAY
}

\author{
Comparative study of medicinal plants related to indigenous and European traditions in \\ Uruguay
}

GREGORIO TABAKIAN'1D

\begin{abstract}
Resumen: Esta investigación presenta información etnobotánica sobre prácticas vinculadas al uso medicinal de plantas en poblaciones urbanas y rurales en los departamentos de Tacuarembó y Canelones, Uruguay. A través del método etnográfico, se realizaron entrevistas semi-estructuradas y de observación participante. A partir de los datos aportados por los entrevistados, se analizaron los conocimientos botánicos locales para su sistematización, comparando los diferentes usos medicinales, su variabilidad de uso en relación al respectivo sistema orgánico, las formas de consumo, las partes utilizadas y el origen de las plantas medicinales (PM) en ambos departamentos. A su vez, se vincularon estos saberes con los orígenes poblacionales (indígena en Tacuarembó; europeo en Canelones). Como resultado, se obtuvo un listado de 138 PM. En ambos departamentos, estas plantas son utilizadas para tratar afecciones similares, principalmente dolencias en los sistemas: digestivo, sensorial y respiratorio. Se puede observar una relación entre la ascendencia de los entrevistados y las formas de uso de ciertas plantas, existiendo una correspondencia entre el origen de la planta y sus prácticas con el aporte poblacional en ambos departamentos. Es de destacar, que en Tacuarembó, la práctica de masticar PM es preponderante con respecto a Canelones, hábito vinculado a tradiciones indígenas.
\end{abstract}

Palabras clave: Etnobotánica, plantas medicinales, saberes populares, Uruguay.

Summary: This research presents ethnobotanical information on practices related to the medicinal use of plants in urban and rural populations in the departments of Tacuarembó and Canelones, Uruguay. Semi-structured interviews and participant observation were carried out using the ethnographic method. Based on the data provided by the interviewees, the local ethnobotanical knowledge was analyzed and then classified, by comparing the different medicinal uses, the variability of use in relation to the organic system, the forms of consumption, the parts used and the origin of the medicinal plants (MP) in both departments. At the same time, this knowledge was linked to the population origins (indigenous, in Tacuarembó, European, in Canelones). The result was a list of $138 \mathrm{MP}$. In both departments, plants are used to treat similar health conditions, mainly diseases of the digestive, sensory and respiratory systems. A relationship can be observed between the descent of the interviewees and the forms of use of certain plants, as there is a link between the origin of the plant and its practices with the population contribution in both departments. It is noteworthy that in Tacuarembó, chewing MP is widespread compared to Canelones; it is a habit linked to indigenous traditions.

Key words: Ethnobotany, medicinal plants, popular knowledge, Uruguay.

\footnotetext{
${ }^{1}$ Escuela Universitaria de Tecnología Médica, Facultad de Medicina (EUTM) de Uruguay, Universidad de la República (UdelaR). E-mail: gregoriotaba@gmail.com
} 


\section{Introducción}

En Uruguay, podemos encontrar importantes antecedentes referidos a plantas útiles en los escritos de cronistas y naturalistas que recorrieron el territorio de la Cuenca del Plata describiendo su entorno natural: Nicolás Monardes (14931588), Pedro Montenegro (1663-1728), Marcos Villodas (1690-1760), Félix de Azara (17421821) y Antonio Pineda (1753- 1792), entre otros (Schiaffino, 1927; Mañé Garzón, 1996; Vera de Flachs \& Page, 2010).

La transferencia de conocimientos sobre las plantas entre el Viejo y el Nuevo mundo ha estado ligada a continuos flujos de intercambio. Muchos de esos conocimientos fueron introducidos en el actual territorio del Uruguay, pero otros provinieron de los grupos indígenas locales. Tal como lo documentan diferentes cronistas durante la conquista y la época colonial, los distintos grupos originarios poseían conocimiento herbolario local, disponiendo del tiempo y las condiciones necesarias para conocer, clasificar y utilizar la gran variedad florística. Por su parte, los viajeros que cruzaron los océanos, trajeron consigo plantas y sus conocimientos asociados, como los relacionados a la medicina de la época, e intentaron incorporar a sus saberes occidentales los conocimientos que poseían los habitantes originarios de la Cuenca del Plata.

La llegada de los jesuitas en los siglos XVII y XVIII, incidió en el desarrollo del estudio de la historia natural en la región (Furlong, 1994). A principios del XIX los textos de los jesuitas fueron la principal fuente de los naturalistas en busca de especies vegetales de uso medicinal (Di Liscia \& Prina, 2002). Durante este siglo surgen distintos trabajos de naturalistas; como la obra del padre Larrañaga (1771-1848), quien recorrió el territorio uruguayo estudiando su flora y su fauna (Larrañaga, 1923). Otro naturalista, Auguste de Saint Hilaire (1799-1853), tiene el mérito de haber descrito científicamente por primera vez la yerba mate: Ilex paraguariensis A. St.-Hil. (Mañé Garzón, 2005).

Entrado el siglo XX, diferentes médicos rurales recorrieron el territorio nacional, relevando diferentes tratamientos de curación mediante el uso de vegetales, animales y minerales. Los registros de la vida campesina rescatados por médicos rurales como Roberto J. Bouton (2014) y Pereda Valdés (1943), dan cuenta, entre tantas otras manifestaciones culturales, de la medicina popular empleada en la zona rural del Uruguay. Otro referente nacional del siglo $\mathrm{XX}$ es el profesor Atilio Lombardo, quien aportó de forma significativa al conocimiento de la botánica en el Uruguay desde sus publicaciones centradas en las plantas nativas y en las propiedades medicinales de las mismas (González et al., 1940; Lombardo, 1964, 1984; Lombardo \& Pou Ferrari, 1970; entre otros). Así mismo, desde diferentes disciplinas comenzaron a estudiarse los usos medicinales de las plantas (Del Puerto, 1969; Del Puerto et al., 1990; Arrillaga de Maffei, 1969, 1997).

En el siglo XXI, se suma un grupo de jóvenes científicos abocados al desarrollo de la etnobotánica. De esta forma, en el año 2011, la Revista Trama, publica un primer Dossier sobre Etnobotánica, (Asociación Uruguaya de Antropología Social y Cultural- AUAS-2011) iniciando esta nueva línea de investigación desde la Antropología. Asimismo, el Anuario de Antropología Social y Cultural, y la Revista Uruguaya de Antropología y Etnografía han publicado diferentes trabajos referentes a la temática. Algunos de ellos pueden verse en Tabakian (2015), Tabakian (2017a, b) y Castiñeira (2017a).

Con el fin de dar continuidad a investigaciones previas en antropología y etnobotánica se propuso estudiar dos zonas geográficas diferenciadas del territorio uruguayo. Estas áreas se encuentran divididas por el río Negro y se diferencian en la composición de su población. Canelones, al sur de dicho río, está caracterizada por una población principalmente descendiente de inmigrantes europeos, mientras que Tacuarembó se ubica al norte y está habitada principalmente por descendientes de pueblos originarios (Fig. 1).

En cuanto a la caracterización ambiental, Uruguay se encuentra en el área biogeográfica denominada pampeana. Si bien, en el territorio confluyen diferentes regiones biogeográficas: paranaense, chaqueña y espinal, se caracteriza por una vegetación con especies herbáceas pampeanas (Achkar et al., 2016). Esta provincia pampeana es de clima templado cálido, con lluvias todo el año, que disminuyen 


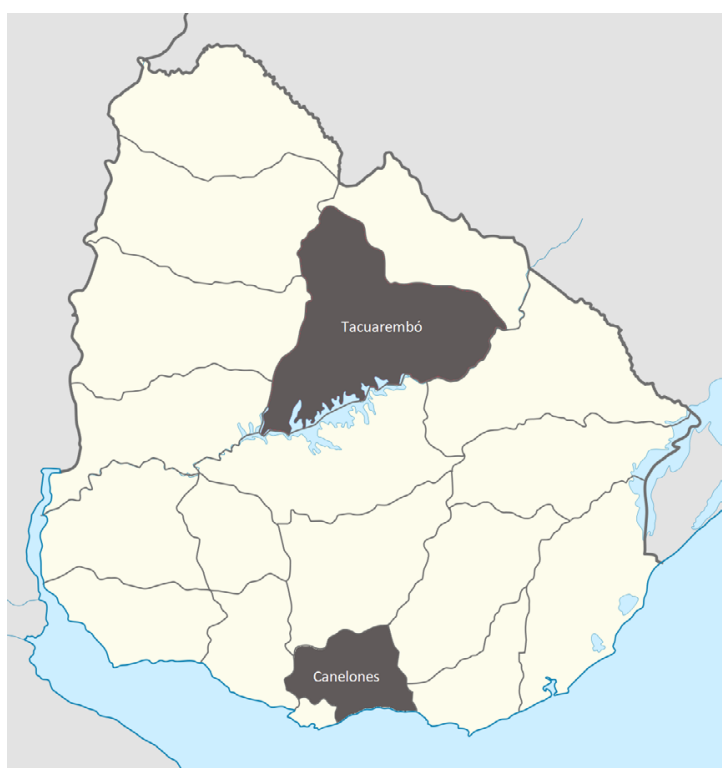

Fig. 1. Mapa de Uruguay y ubicación geográfica de los departamentos de Canelones y Tacuarembó.

Fig. 1. Map of Uruguay and the geographic location of Canelones and Tacuarembó departments.

de norte a sur y de este a oeste, incidiendo en la vegetación (Cabrera \& Willink, 1980).

Actualmente se reconocen en el territorio cerca de 2.600 especies de herbáceas, helechos, gramíneas, leñosas, tanto nativas como adventicias, que crecen en variados ambientes (Achkar et al., 2016). El monte indígena ocupa distintos ámbitos, como montes de galería o ribereño, monte de parque, monte de quebrada y monte serrano (Muñoz et al., 2007).

Si bien la región sur del territorio, el departamento de Canelones, cuenta con vegetación de la región pampeana, la zona noreste de Uruguay, especialmente los departamentos de Tacuarembó y Rivera, se ven influenciados por especies de la región paranaense. Así mismo, podemos encontrar bosques serranos y bosques parque en esta área (Achkar et al., 2016).

El clima de Uruguay es relativamente uniforme, no existiendo diferencias significativas entre los puntos extremos del territorio. Clima templado, subtropical, semi-húmedo, con abundantes precipitaciones. La temperatura anual promedio es de $16^{\circ} \mathrm{C}$, aumentando de sur a norte por la disminución de la latitud.

\section{Recorrido etnográfico}

A nivel social, en la actualidad, el medio rural uruguayo presenta múltiples pueblos, centros poblados y parajes con una trayectoria histórica, que se caracterizan por presentar un estancamiento demográfico, y en algunos casos, una marcada tendencia a la desaparición. Las comunidades seleccionadas para este estudio están actualmente sometidas a una situación de profundo envejecimiento de la población, como resultado de la constante emigración de sus jóvenes, acarreando con ello la interrupción en la transmisión de conocimientos botánicos locales.

El departamento de Tacuarembó (Fig. 2) está ubicado en el centro-norte del territorio uruguayo, es el mayor en superficie del país $\left(15.438 \mathrm{~km}^{2}\right)$.

$\mathrm{Su}$ población es de 90.053 habitantes, 44.169 hombres y 45.884 mujeres. El 89,2\% de la población de Tacuarembó reside en zonas urbanas, mientras que el 10,8\% restante vive en áreas rurales. Su capital, la ciudad de Tacuarembó, nuclea el $60,8 \%$ de la población urbana con un total de 54.757 habitantes: 26.332 hombres y 28.425 mujeres (INE, 2011).

Tacuarembó fue creado el 14 de junio de 1837, y comprendía también el actual territorio del departamento de Rivera. El nombre Tacuarembó es de origen guaraní (Tacuaremboty, que significa lugar de cañaverales o lugar de tacuarales, en referencia al nombre que reciben distintas especies del género Merostachys) y se remonta a fines del siglo XVII, cuando así lo denominaron los indígenas misioneros que realizaban las vaquerías (Barrios Pintos, 2000).

En épocas históricas todo el territorio al norte del río Negro formó parte de las estancias misioneras: Yapeyú y San Borja, contando cada una de ellas con varios puestos de estancias $\mathrm{y}$ una numerosa población proveniente de los pueblos misioneros (Curbelo, 2009). Es justamente la presencia misionera indígena uno de los componentes poblacionales más importantes de la región; la misma los relaciona como pobladores en los puestos de estancias; prófugos, huidos de los pueblos misioneros; mano de obra, traídos para la construcción de obras militares durante la colonia; soldados de la corona, integrando los ejércitos que enfrentaron principalmente a portugueses e indígenas infieles; desplazados sociales luego de 
la expulsión de los jesuitas y durante el período patrio (Barreto \& Curbelo, 2009). También debemos considerar la presencia de indígenas charrúas y minuanes, principalmente durante el siglo XIX, ya que en la región ocurrieron numerosas matanzas desde 1801 (la campaña de exterminio conducida por el capitán del cuerpo de Blandengues, Jorge Pacheco) o la última de estas en 1831 (Salsipuedes y Mataojo), así como la desaparición de uno de sus últimos caciques (Acosta \& Lara, 1981, 1989; Cabrera Pérez \& Barreto, 2006).

Otro componente importante en la zona es la población de origen africano (esclava o liberta) traída por estancieros brasileños que se establecieron mayormente desde 1820 . Con respecto al aporte brasileño, constituyó una fuerte corriente inmigratoria, instalándose principalmente al norte del país (Vidart \& Pi Hugarte, 1969). Por último, se deben considerar los aportes de la inmigración ultramarina, principalmente a partir del último tercio del siglo XIX, con la llegada de italianos y vascos.

De esta manera, el departamento se fue poblando con la influencia de diferentes grupos culturales, con un importante aporte poblacional indígena en sus orígenes.

El departamento de Canelones (Fig. 3), está situado al sur del territorio uruguayo, posee 520.187 habitantes (253.124 hombres y 297.063 mujeres), concentrando la mayor población del país después de Montevideo (INE, 2011). Esta zona se caracteriza por el predominio de la horticultura, la fruticultura y la vitivinicultura (Achkar et al., 2016).

$\mathrm{Su}$ territorio formaba parte de la jurisdicción de Montevideo hasta 1816, momento en que es creado el departamento por José Gervasio Artigas. Su denominación proviene de los arroyos Canelón Chico y Grande, en cuyas orillas abundaba el árbol de igual nombre, Myrsine laetevirens (Mez) Arechav. (Barrios Pintos, 1981). El gentilicio de los habitantes de Canelones no es "canelonenses" sino "canarios"; denominación debida a que la mayor parte de la población desciende de naturales de las islas Canarias (Barrios Pintos, 1981). Vidart (1969) considera que la zona sur del país, y en especial en el departamento de Canelones, se caracteriza por un "tipo humano campesino" que denomina "chacarero". Este es el agricultor extensivo, dedicado a los cultivos de trigo, maíz, tubérculos y hortalizas; de ascendencia mayoritariamente canaria y nivel económico bajo; aplica técnicas primitivas en sus labores agrícolas (el empleo de rastras y el arado tirado por bueyes, entre otros ejemplos) y realiza un trabajo generalmente familiar (Vidart, 1969; Barrios Pintos, 1981; Barreto, 2008).

Los inmigrantes transmitieron a las siguientes generaciones no sólo sus conocimientos en relación a las tareas agrícolas, sino también aspectos de la cultura canaria, especialmente los relacionados a la medicina popular (Vidal \& Pi-Hugarte, 1969; Barreto, 2008). Por otra parte, el establecimiento de estos colonos en el siglo XIX produjo cambios en el entorno rural del departamento de Canelones; que pasó de ser una región exclusivamente ganadera (conformaba parte de las estancias repartidas a los primeros pobladores de Montevideo en el siglo XVIII), a una zona exclusivamente agrícola.

Vidart \& Pi-Hugarte (1969) mencionan que existen múltiples manifestaciones culturales legadas de la variedad de grupos de inmigrantes llegados en diferentes oleadas al Uruguay (particularmente canarios, vascos e italianos).

A partir del año 2003 comenzó a ejecutarse en amplias zonas de Canelones (Tala, El Santoral y Los Cerrillos) el proyecto Canarios de ayer y de hoy: la presencia canaria en el Uruguay a través de un enfoque biodemográfico. Los principales resultados indican que estos inmigrantes provienen principalmente de dos islas del Archipiélago Canario: Lanzarote y Fuerte Ventura; se constata una amplia red migratoria que atrae a familias enteras, así como un número importante de mujeres canarias que arribaron solas con sus hijos; y presentan valores elevados de endogamia y consanguinidad, lo que contribuyó a reforzar y reafirmar la identidad canaria. En lo que respecta a la población descendiente de estos canarios, se realizaron entrevistas en ámbitos urbanos y rurales, en las cuales se detectaron abuelos/as canarios/as (48\%) y bisabuelos/as (46\%), determinándose a su vez que el $62 \%$ de esta descendencia vive aún en la misma tierra heredada por sus abuelos o bisabuelos canarios. El alcance temporal de la reconstrucción es de cinco generaciones y está acotada por la llegada en el siglo XIX de estos inmigrantes. 
Dada esta diferenciación en relación al aporte poblacional de ambos departamentos: predominantemente indígena en Tacuarembó y predominantemente europeo en Canelones, este trabajo se propuso conocer si existen particularidades en cuanto al uso de plantas medicinales, y vincular, a su vez, estos conocimientos con los orígenes poblacionales.

\section{Materiales y Métodos}

Esta investigación se llevó a cabo entre los años 2014 y 2015. Para responder a los objetivos propuestos, se incluyeron en el trabajo de campo, entrevistas semi-estructuradas e informales y observación participante (Taylor \& Bogdan, 1992; Martin, 1995; Guber, 2011) en los departamentos de Tacuarembó y Canelones, Uruguay. Se entrevistaron diferentes actores sociales vinculados al uso de plantas medicinales: vendedores y recolectores; herbolarias/os; abuelas/os; curanderos/as, profesionales de la salud y otros profesionales relacionados al uso de plantas con fines medicinales. Se indagó en diferentes espacios de sociabilización, como ferias y herboristerías, así como los conocimientos que poseen los pobladores de mayor edad. Todos los actores entrevistados son personas que conocen y utilizan plantas como medicinas, y a su vez, fueron señalados, en las diferentes localidades, como los portadores de estos conocimientos.

Las poblaciones relevadas en el departamento de Tacuarembó, fueron las ubicadas en el espacio territorial constituido por la ruta 5 , de sur a norte: Paso de los Toros (12.985 hab.), Estación Chamberlain (52 hab.), Cuchilla de Peralta (218 hab.), Curtina (1.037 hab.), Paso Bonilla (510 hab.), Ciudad de Tacuarembó (54.757 hab.); la ruta 26 de sur a noroeste: Las Toscas (1.142 hab.), Pueblo del Barro (98 hab.), Ansina (2.712 hab.), Pueblo de Arriba (170hab.), Rincón de la Aldea (S/d), Valle Edén (S/d), y al norte del departamento, Laureles (19 hab.), (INE, 2011).

Se realizaron un total de 34 entrevistas semiestructuradas ( $44 \%$ mujeres y $56 \%$ hombres) y 8 entrevistas informales. La edad promedio de los entrevistados fue de 60 años.

En el departamento de Canelones se estudió la zona noroeste. Las poblaciones seleccionadas fueron: Ciudad de Canelones (19.865 habitantes); sobre ruta 6: Sauce (6.132 hab.); Santa Rosa (3.727 hab.); San Bautista (1.973 hab.); Castellanos (520 hab.) y Paraje Paso la Paloma (S/D) (INE, 2011).

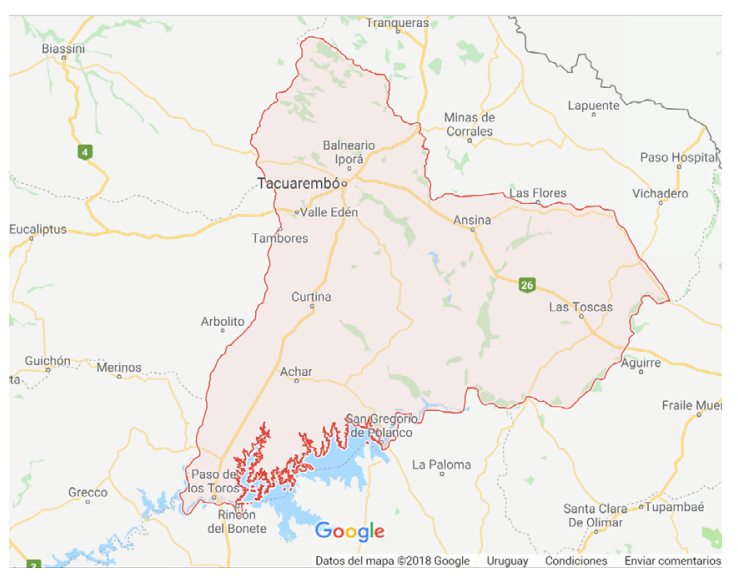

Fig. 2. Departamento de Tacuarembó. Fuente: Google Map.

Fig. 2. Department of Tacuarembó. Source: Google Map.

Se realizaron 14 entrevistas formales $(86 \%$ mujeres y $14 \%$ hombres). La edad promedio de los entrevistados fue de 67 años.

Varias de las entrevistas fueron documentadas en formato audiovisual con la finalidad de realizar un documental del proceso investigativo (Tabakian, 2016). También se utilizaron registros fotográficos. Las imágenes facilitaron la identificación, sistematización y catalogación de las plantas medicinales nombradas. Se recolectó material botánico de referencia el cual se halla depositado transitoriamente en la Facultad de Humanidades y Ciencias de la Educación, UdelaR, y se confeccionó un herbario fotográfico. Así mismo, la mayoría de las plantas pueden verse en diferentes videos realizados, de identificación y colecta de especies (Tabakian, 2012).

La identidad botánica fue asignada siguiendo la nomenclatura aceptada por el Catálogo de las Plantas Vasculares del Conosur (IBODA, 2019) y The Plant List (2013) en el caso de las especies cultivadas. 


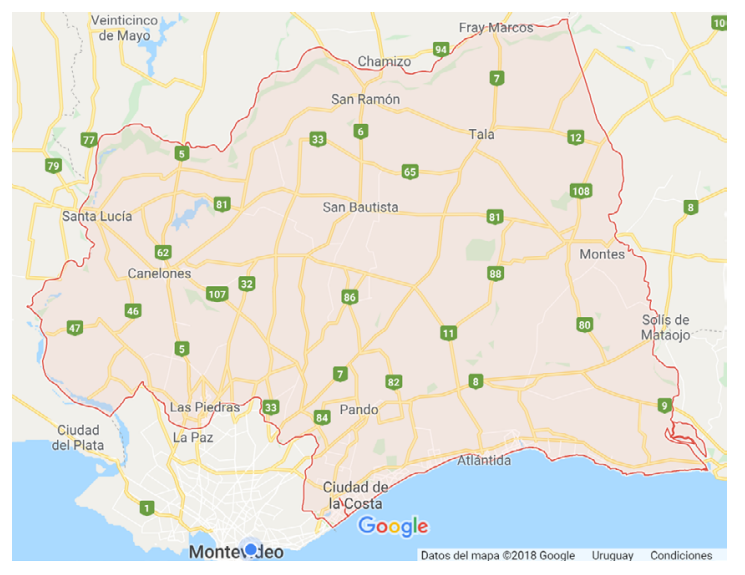

Fig. 3. Departamento de Canelones. Fuente: Google Map. Fig. 3: Department of Canelones. Source: Google Map.

La identificación de las plantas fue realizada mediante bibliografía especializada (Alonso et al., 2008; Del Puerto et al., 1990; Lombardo, 1964; Muñoz et al., 2007; Ratera \& Ratera, 1980), consultas con especialistas y en particular con Marión Aguilera (herbolaria, ex funcionaria del Jardín Botánico de Montevideo, quien trabajó junto al botánico Atilio Lombardo).

Durante todo el proceso se contemplaron los aspectos éticos, utilizando el consentimiento informado así como la autorización para el uso de imágenes.

\section{Resultados y Discusión}

Entre ambos departamentos se nombraron en total 183 plantas medicinales, 121 en Tacuarembó y 62 en Canelones. De este total, se identificaron 138 plantas: 74 en Tacuarembó, 17 en Canelones y 47 compartidas. A partir de estos datos se analizaron y sistematizaron sus diferentes usos medicinales. Una de las primeras observaciones refiere a la nomenclatura local, encontrando una gran variedad de nombres populares para una misma planta. A su vez, un mismo nombre popular, es utilizado para referir a especies diferentes según la zona sur o norte del país, posiblemente vinculados con el origen de su uso, objetivo de este trabajo.

En la Tabla 1 se presentan las 121 especies diferentes de PM registradas en el departamento de Tacuarembó, sus nombres locales e identificación botánica cuando fue posible, usos, formas y partes utilizadas y número de menciones. Tanto en este caso, como en el caso de las PM de Canelones, se consideró una mención por persona, por cada planta mencionada, independientemente de la cantidad de usos que se le atribuyeran. Las plantas medicinales mencionadas con mayor frecuencia (entre 21 y 6 menciones, sobre 34 entrevistados) son: menta/ hierba buena, marcela, salvia, carqueja, cedrón, guazatumba, palma imperial, romero, cola de caballo, arrayán, malva, marrubio, mercurio, suelda consuelda/confrey, llantén, naranjo, rompe o quiebra piedra, ruda, yerba carnicera, guaco, zarzaparrilla, aloe, árnica, mburucuyá, bardana, cambará, congorosa, coronilla, uña de gato y anacahuita.

Por su parte, en el departamento de Canelones, se nombraron 62 especies de PM diferentes (Tabla 2). Las plantas medicinales nombradas con mayor frecuencia son (entre 9 y 2 menciones, sobre 14 entrevistados): malva, ortiga, higuera, salvia, llantén, marrubio, ruda, guaco, hierba del pollo, marcela, ajenjo, anacahuita, cedrón, eucaliptus, palma imperial, aloe, amapola, duraznillo, manzanilla, melisa/toronjil, pata de vaca, santa maría, yerba carnicera, bardana, carqueja, cola de caballo, cuerno del diablo, floripón, granada y guayabo.

Analizando las Tablas 1 y 2, se puede observar que de las treinta principales PM nombradas, hay 13 PM que son compartidas entre ambos departamentos, representando el $43 \%$ de las principales PM mencionadas (malva, salvia, llantén, marrubio, ruda, guaco, marcela, anacahuita, cedrón, palma imperial, aloe, carqueja y cola de caballo).

Para el caso de Tacuarembó, las 121 PM nombradas, son utilizadas para tratar 76 afecciones diferentes. En el caso de Canelones, las 62 PM nombradas, son utilizadas para tratar 36 afecciones. Los actores entrevistados al hacer referencia a una PM en particular, nombran varios usos terapéuticos, dando como resultado que cuantas más menciones reciba una planta, mayor es la variabilidad de usos terapéuticos que presenta. Debido a la gran cantidad de usos, se decidió considerar hasta tres dolencias máximo en que actúa la PM sobre un órgano específico. 


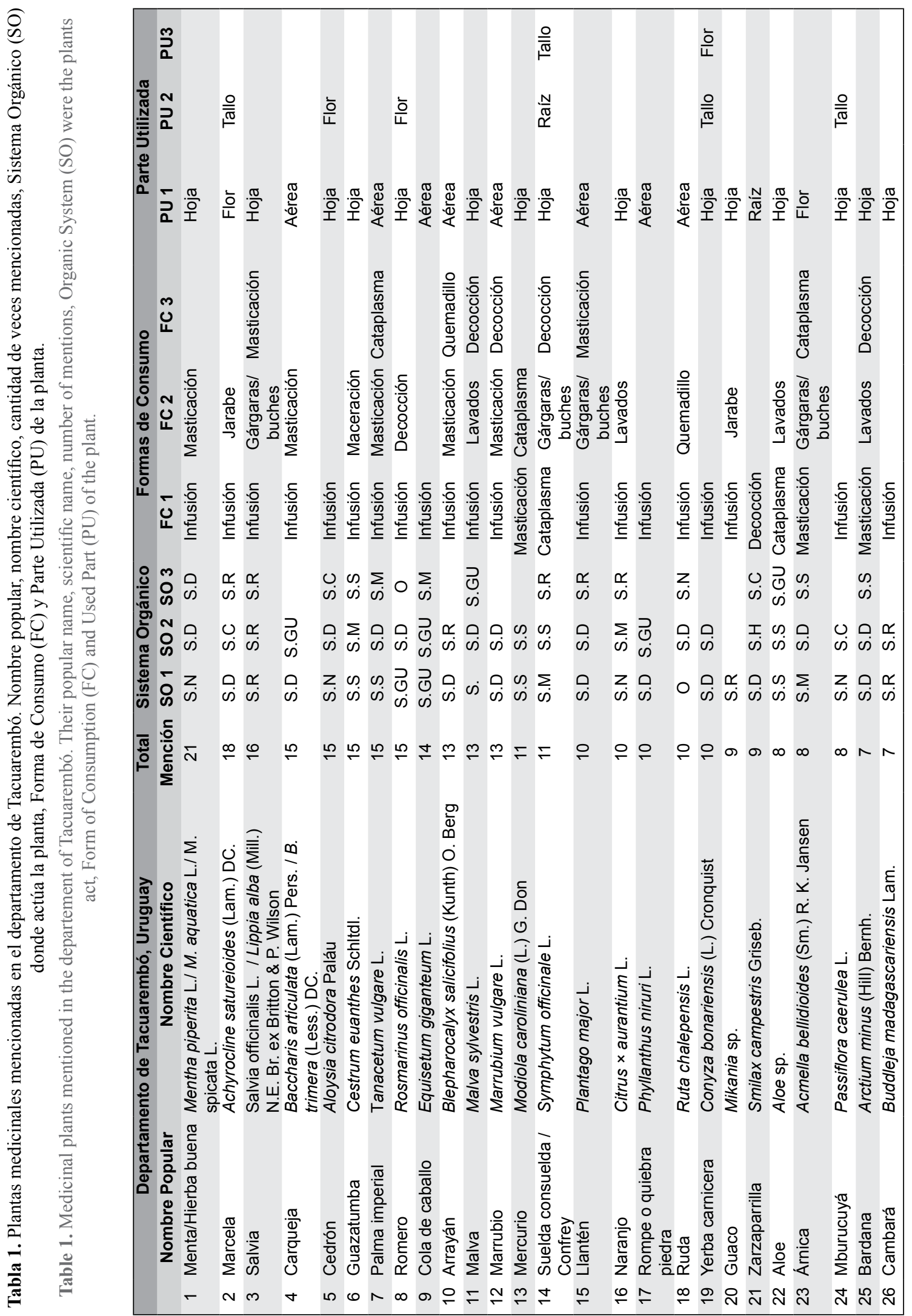




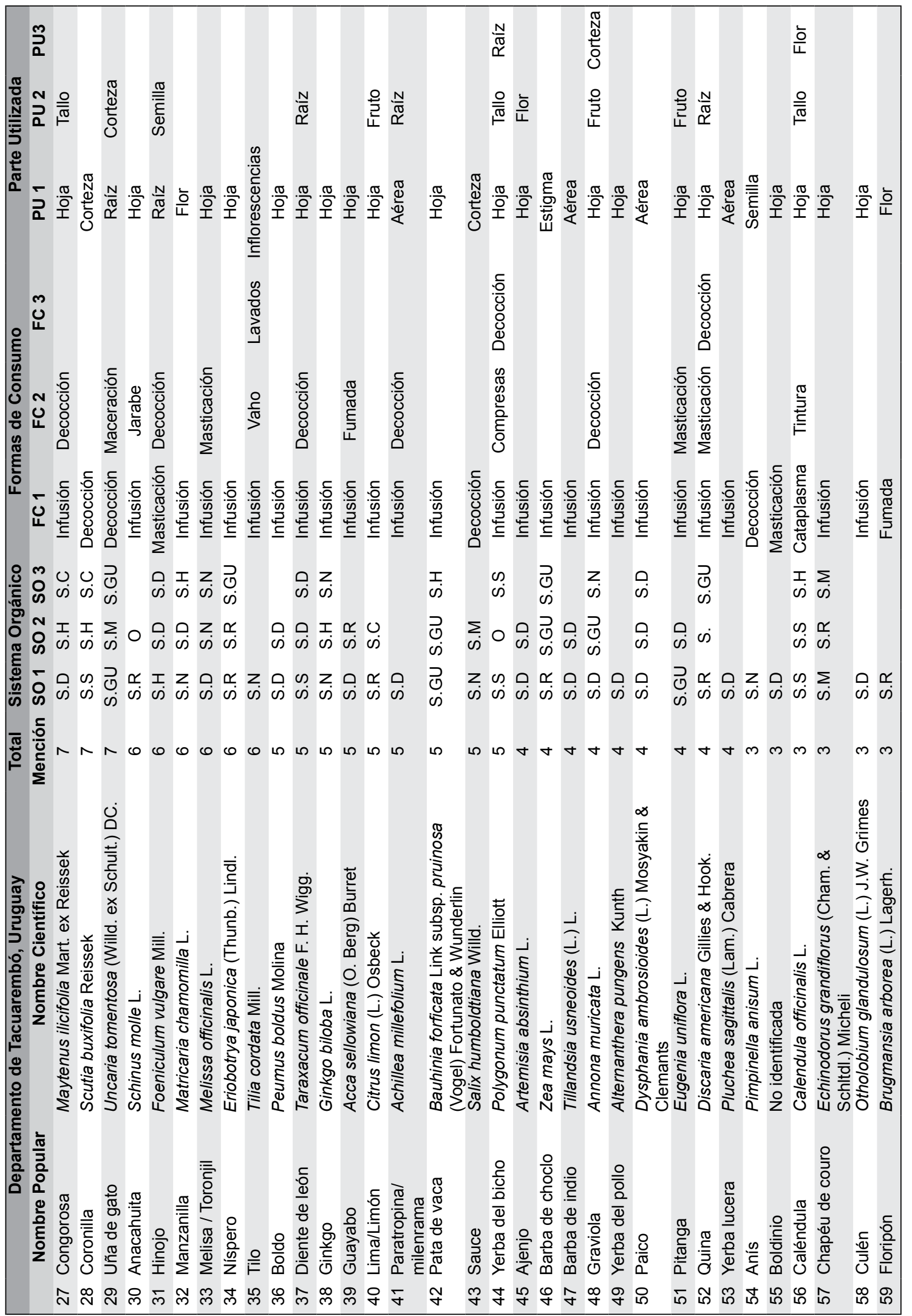




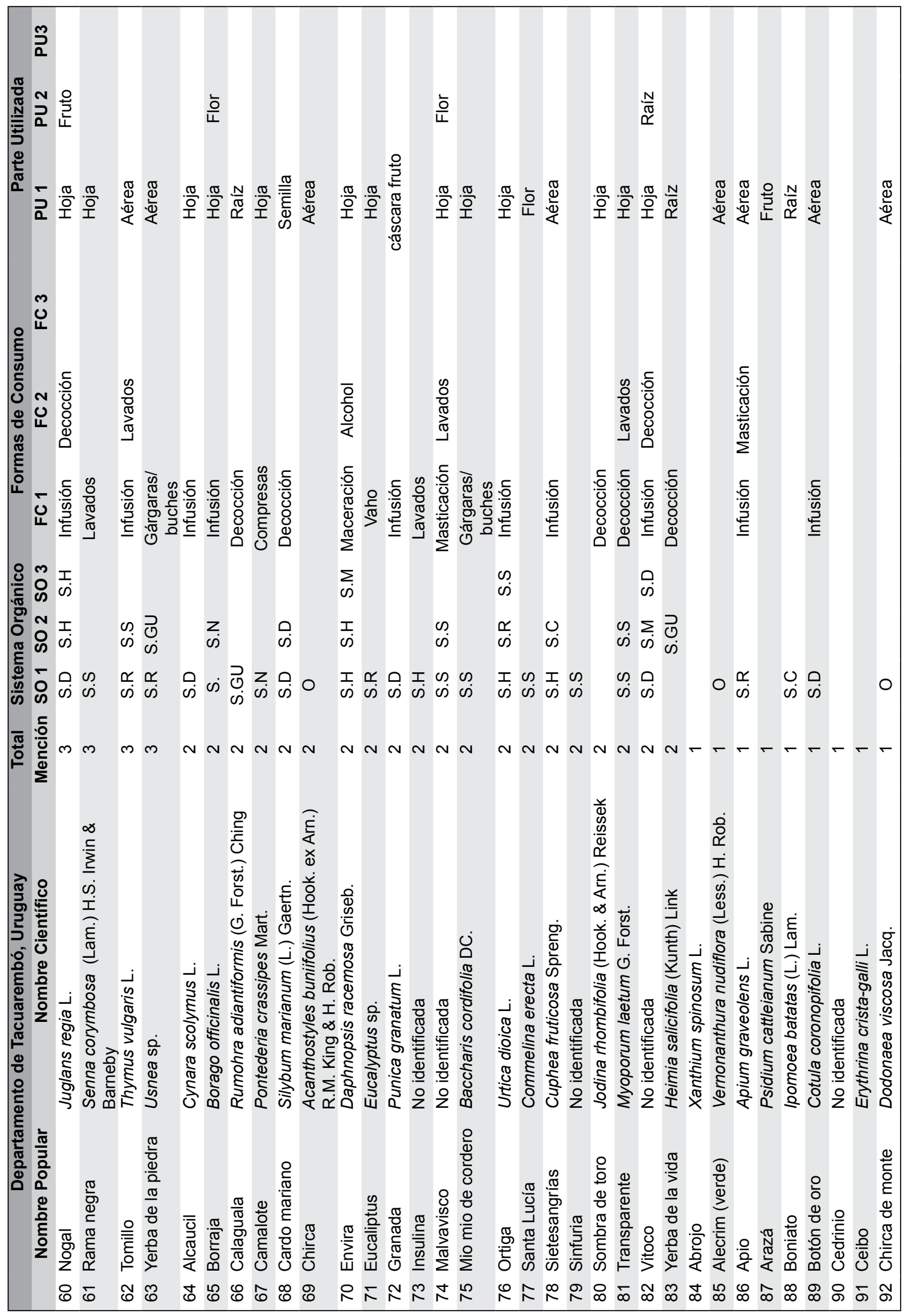




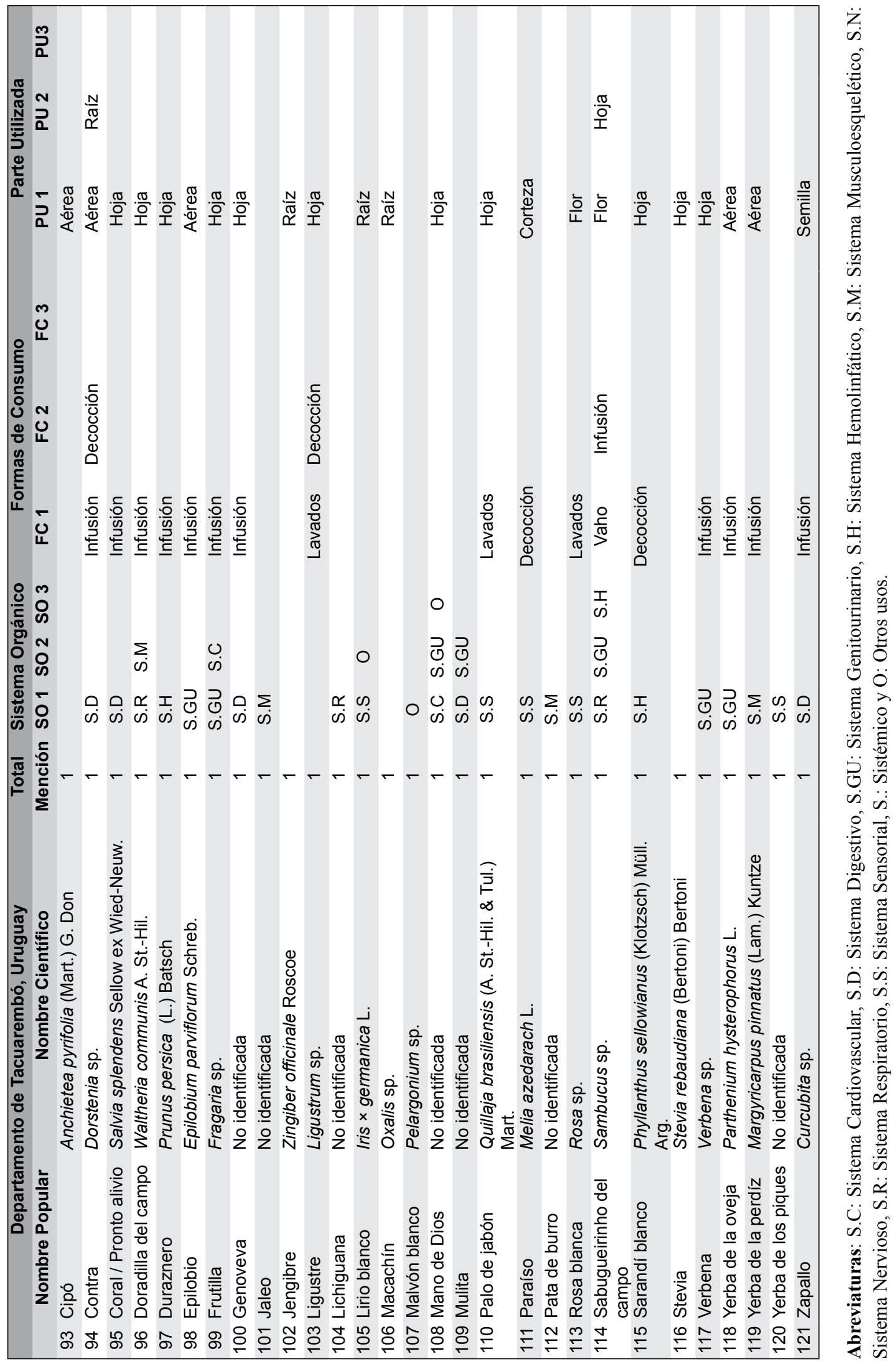




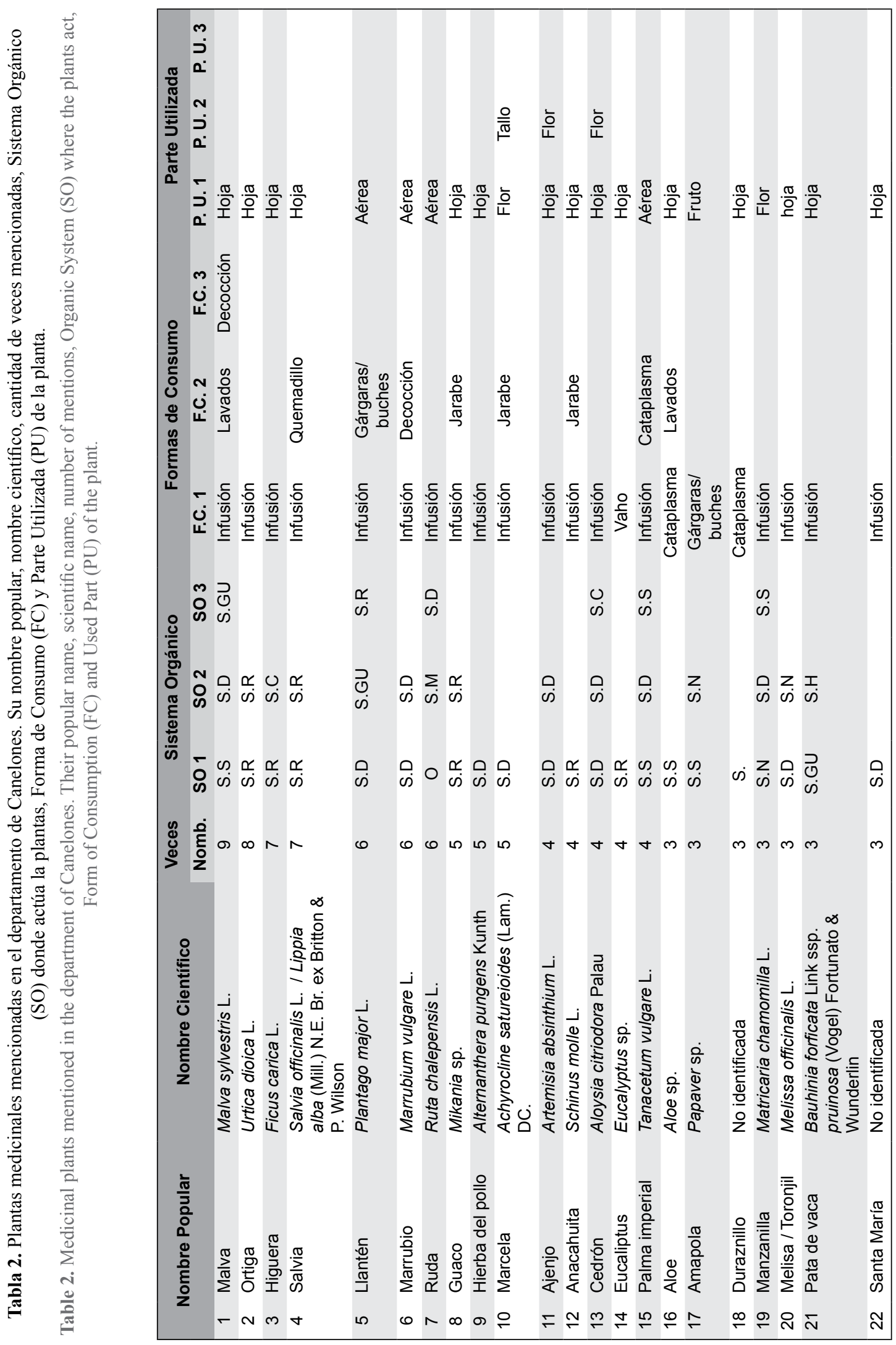




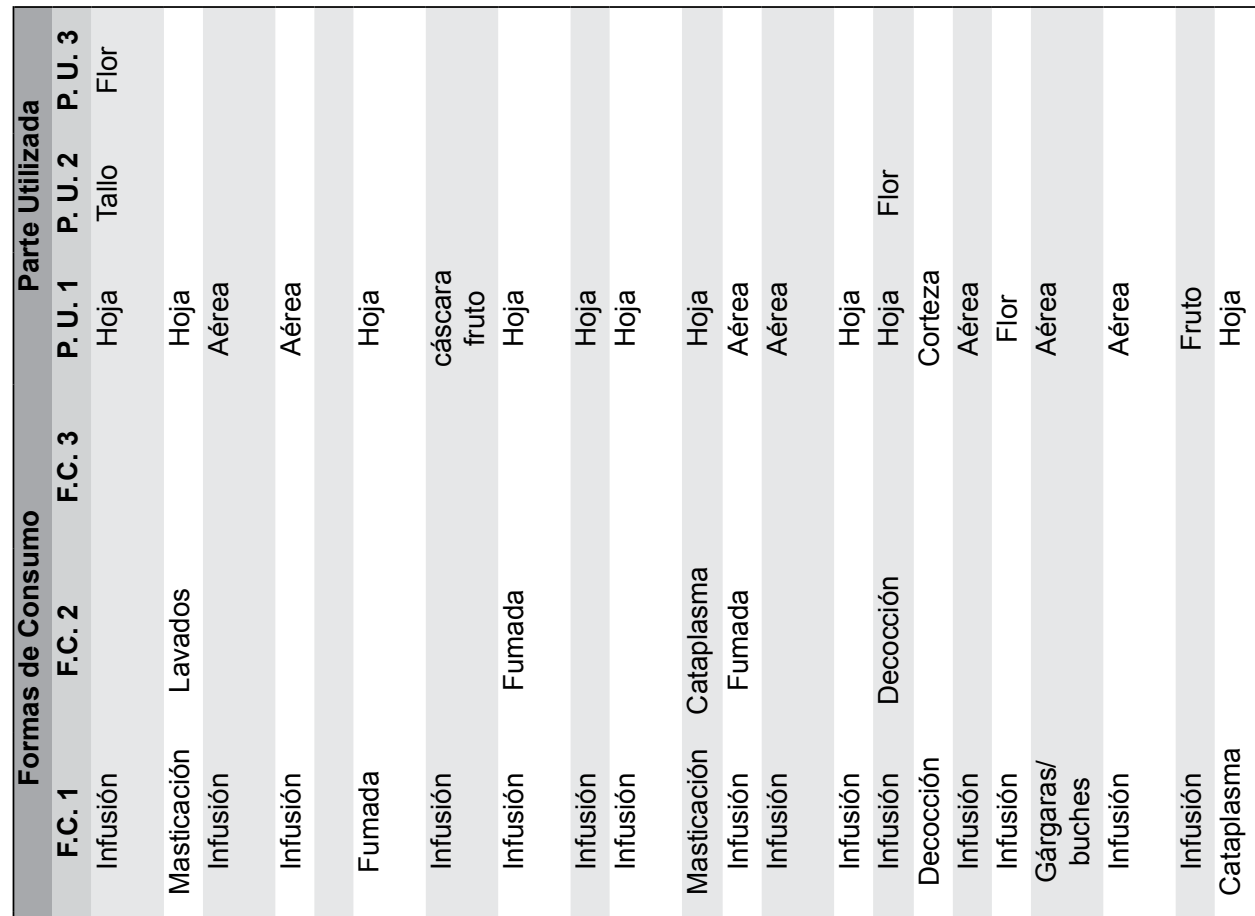

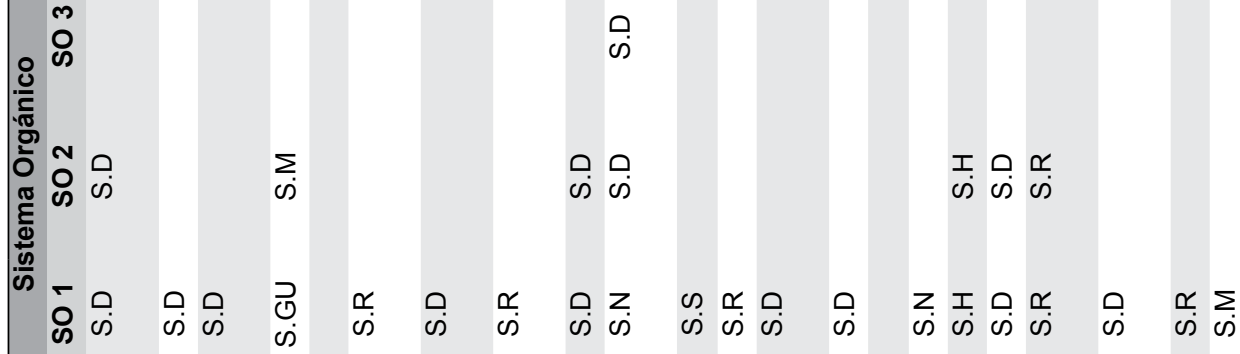

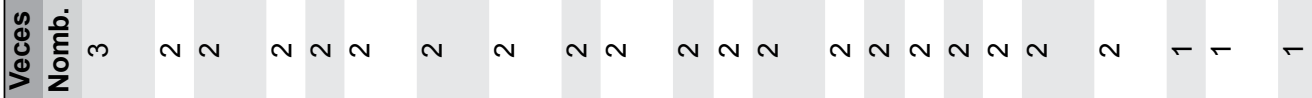

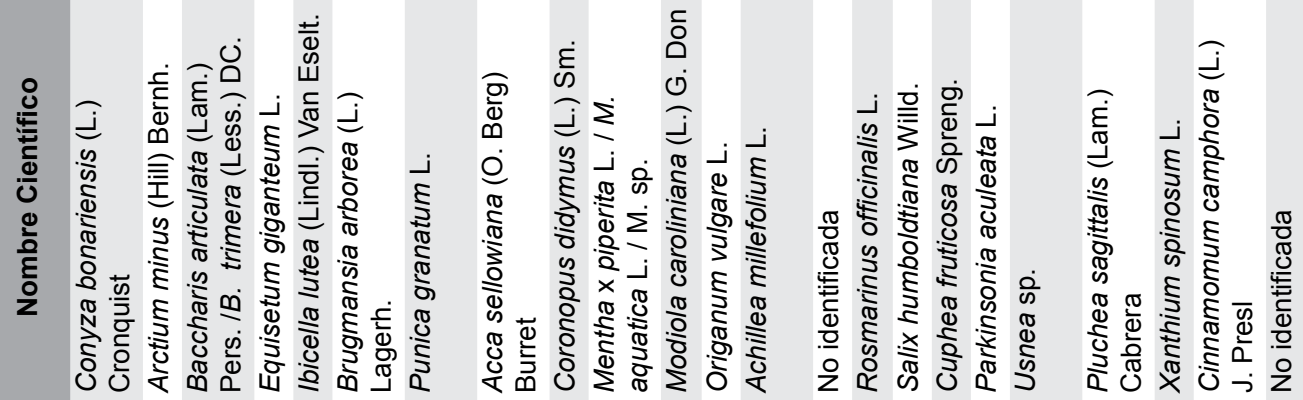

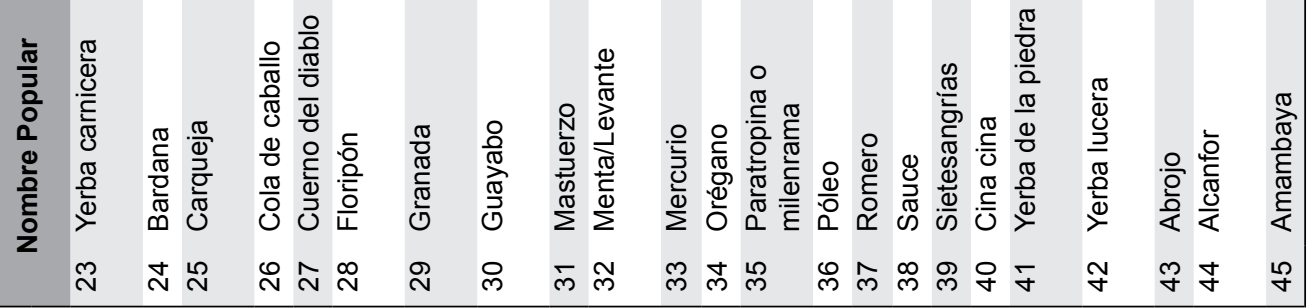




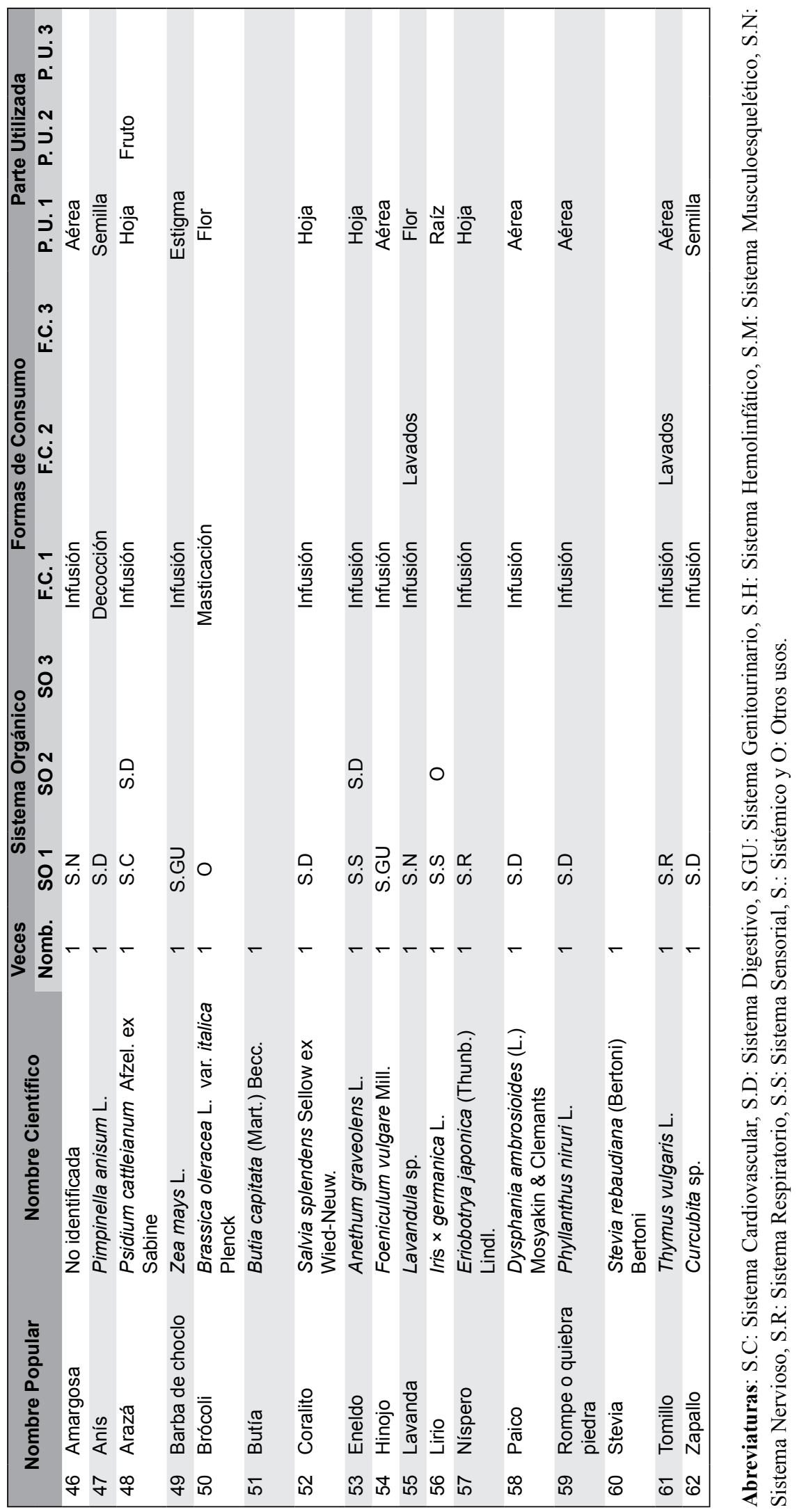


De igual modo, dada la extensión del listado de afecciones tratadas, se organizaron las dolencias referidas, según diferentes Sistemas Orgánicos, tomando como base el Manual Merck de información médica general (Berckow et al., 1997). De esta manera, se agruparon las afecciones en diez Sistemas Orgánicos diferentes en donde actúa la PM: Sistema Cardiovascular (SC), Sistema Digestivo (SD), Sistema Genitourinario (SGU), Sistema Hemolinfático (SH), Sistema Musculoesquelético (SM), Sistema Nervioso (SN), Sistema Respiratorio (SR), Sistema Sensorial (SS), Sistémico (S) y Otros usos (O).

Puede determinarse que en ambos departamentos se utilizan PM para tratar afecciones similares; principalmente para tratar órganos de los sistemas: digestivo, sensorial y respiratorio. En estos tres sistemas de órganos, si bien varían los datos porcentuales, se presentan las principales dolencias tratadas con PM en ambos departamentos (Figs. 4 y 5).

\section{Usos terapéuticos y variabilidad de usos}

Como ya se mencionó, una de las observaciones realizadas, válida en ambos departamentos, es que cuantas más veces es mencionada una determinada PM, mayor es su variabilidad de usos medicinales. Esto permitió conocer sobre cuántos órganos diferentes puede actuar una misma planta. Es por esta razón que para el análisis de estos datos se consideraron las PM que fueron nombradas en más de tres oportunidades en ambos departamentos. De esta manera, para el caso de Tacuarembó, 70\% de las PM actúan sobre dos o más órganos del Sistema Orgánico, sirviendo cada una de estas PM para tratar afecciones en diferentes órganos del cuerpo humano.

En el caso de Canelones, se obtuvo que $43 \%$ de las PM nombradas más de tres veces, actúan sobre dos o más órganos del sistema orgánico, mientras que $57 \%$ actúa sobre un solo órgano.

\section{Parte utilizada}

Las partes utilizadas de la PM son variadas: hoja, parte aérea, cáscara del fruto, corteza (denominada entrecáscara por algunos entrevistados), estigma, flor, fruto, inflorescencias, raíz, semilla y tallo. Las Figs. 6 y 7 muestran que la hoja, la parte aérea y

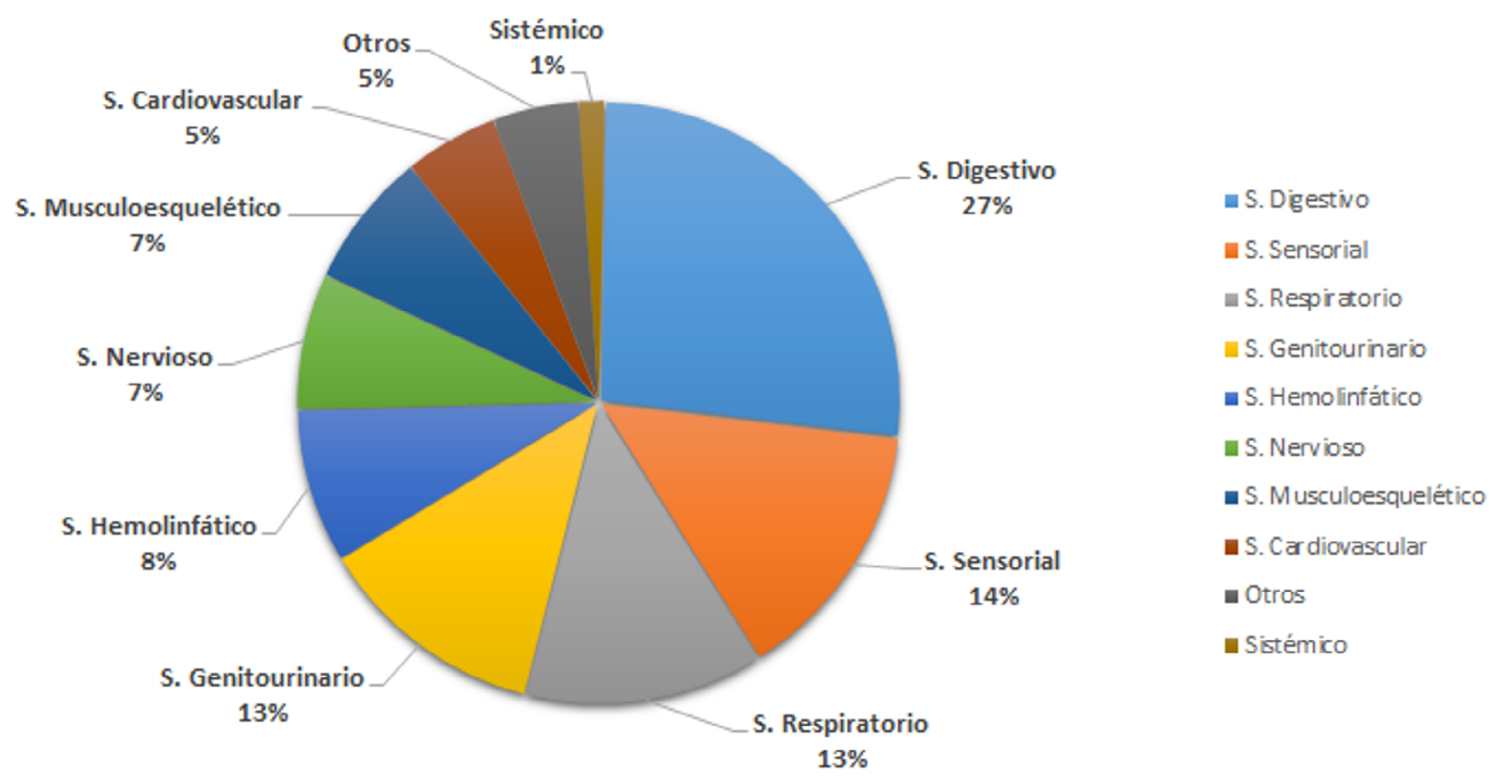

Fig. 4. Sistema orgánico donde actúan las plantas medicinales, Tacuarembó.

Fig. 4. Organic System where the medicinal plants act, Tacuarembó. 


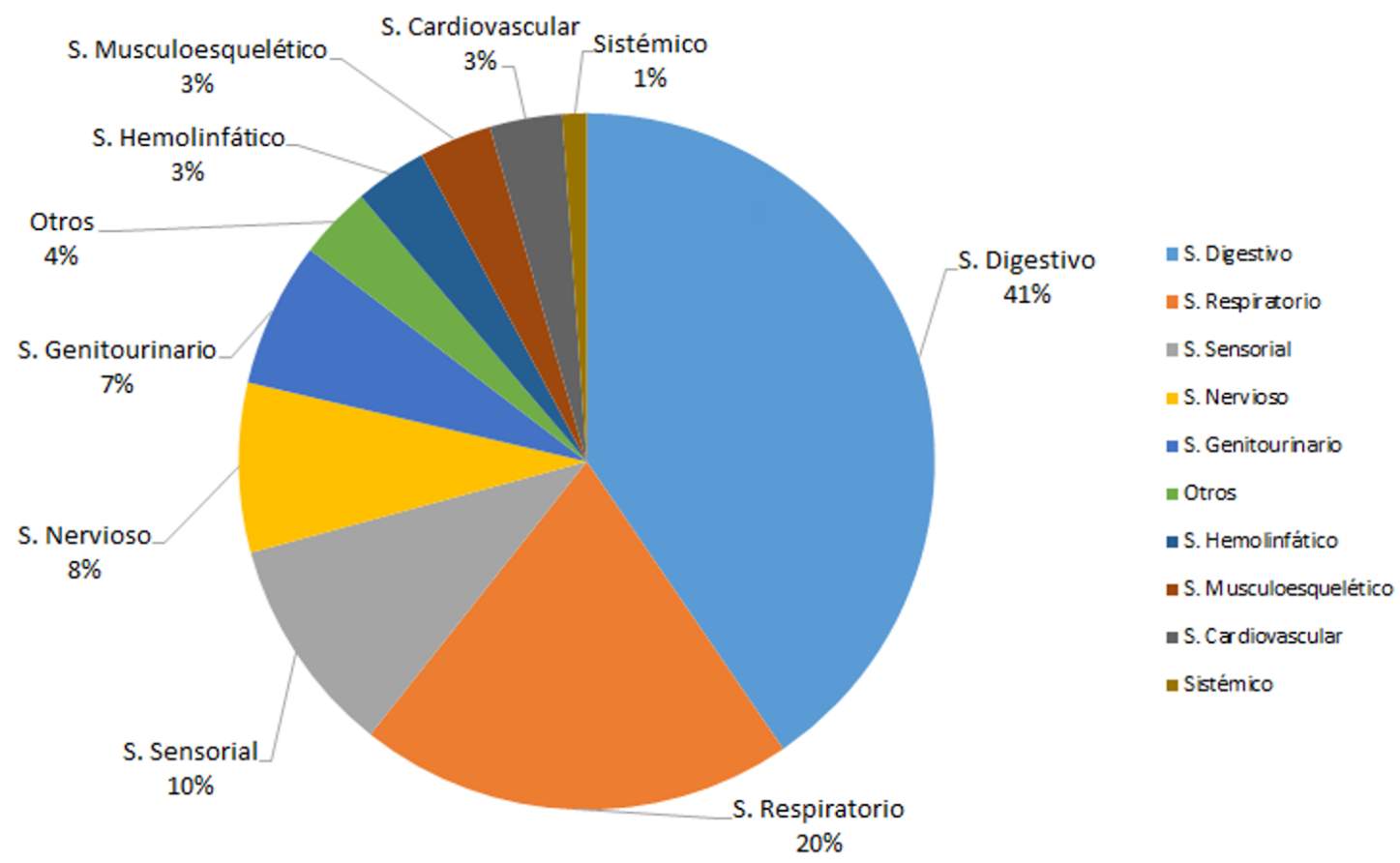

Fig. 5. Sistema orgánico donde actúan las plantas medicinales, Canelones.

Fig. 5. Organic System where the medicinal plants act, Canelones.

la flor son las principales partes de las PM utilizadas en ambos departamentos. Se destaca en Tacuarembó el uso de la raíz como una de las principales partes utilizadas.

\section{Formas de consumo}

La forma de consumo de las PM también son muy variadas: cataplasma, compresa, decocción, fumada, gárgaras/buches, infusión, jarabe, lavado, maceración, masticación, quemadillo, tintura y vaho.

La infusión es la forma de consumo predominante en ambos departamentos. Una particularidad hallada en el departamento de Tacuarembó es la masticación. La práctica de masticar plantas medicinales tiene una significativa ventaja numérica con respecto a Canelones. Al indagar sobre esta forma de aliviar dolencias, varios de los entrevistados en Tacuarembó hicieron referencia a la posible raíz indígena de esta tradición (esta cuestión se desarrolla más adelante, cuando se vincula la ascendencia con el consumo de PM).
Ascendencia de los actores entrevistados y su vinculación al uso de PM

En el departamento de Tacuarembó, de los entrevistados que nombraron PM, sin tener en cuenta médicos y otros profesionales, el $53 \%$ tiene al menos un ascendente brasileño (en sentido amplio, puede significar un ascendente indígena, africano, europeo o todos), $27 \%$ un ascendente indígena, $20 \%$ un ascendente europeo y $16 \%$ dice ser nativo de la región (en sentido amplio, puede significar un ascendente indígena, africano, europeo o todos).

Para este análisis se tuvieron en cuenta, para el departamento de Tacuarembó, solo los descendientes de indígenas. De esta manera, el 27\% de los actores con ascendencia indígena hicieron referencia a $21 \mathrm{PM}$ que eran utilizadas por los grupos indígenas que habitaron la región: árnica, barba de indio, calaguala, carqueja, chapéu de couro, coronilla, guayabo, guazatumba, llantén, malvavisco, marrubio, mburucuyá, melisa, 


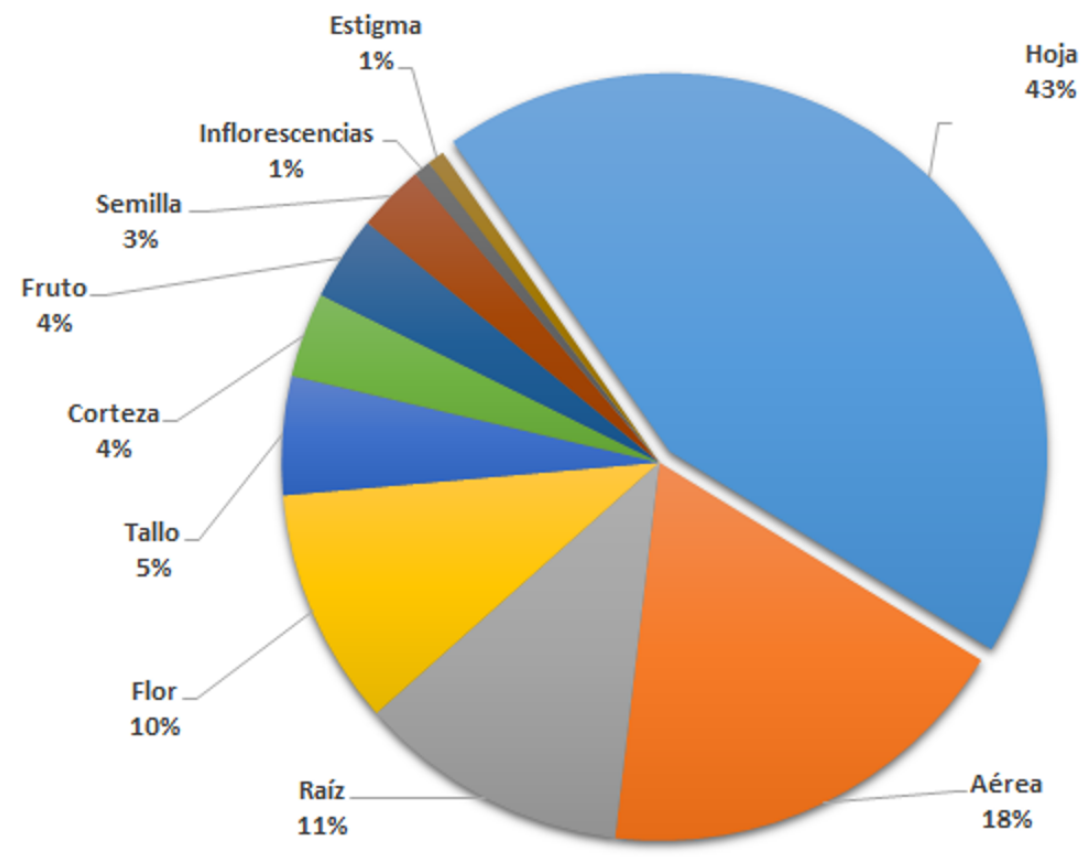

\begin{tabular}{|c|}
\hline 口 Hoja \\
\hline Aérea \\
\hline घaíz \\
\hline Flor \\
\hline vallo \\
\hline Corteza \\
\hline Fruto \\
\hline Eemilla \\
\hline Inflorescencias \\
\hline Estigma \\
\hline
\end{tabular}

Fig. 6. Parte utilizada de las plantas medicinales en Tacuarembó.

Fig. 6. Used parts of the medicinal plants in Tacuarembó.

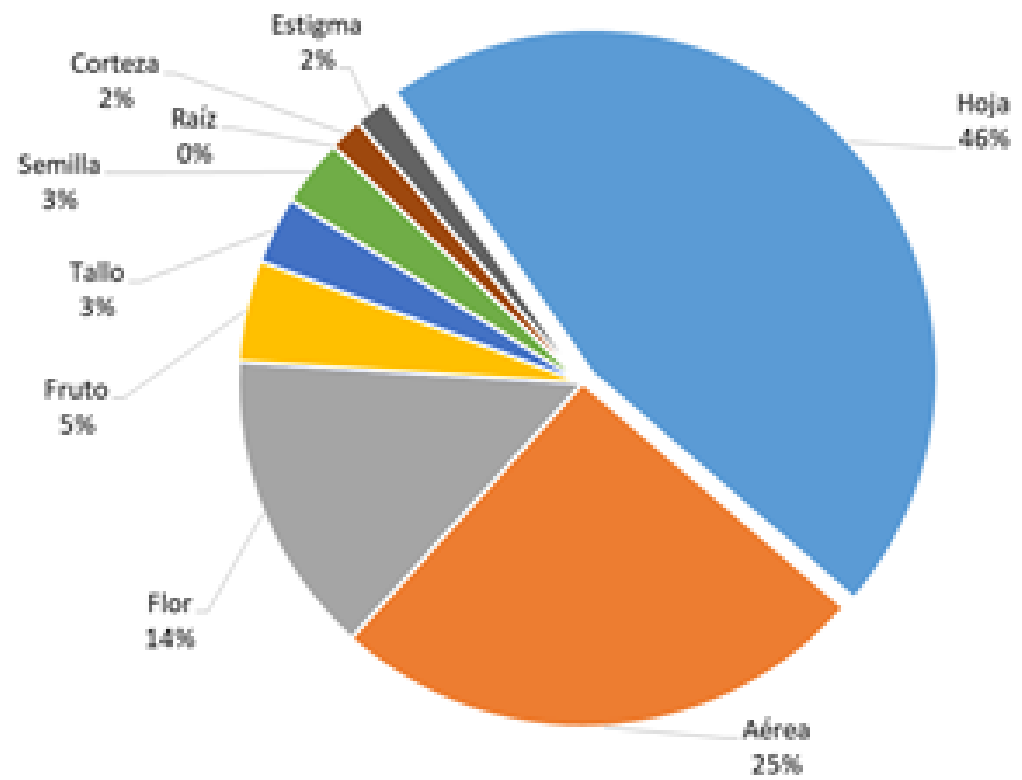

$$
\begin{aligned}
& \text { = Hoja } \\
& \text { = Aérea } \\
& \text { = Flor } \\
& \text { = Fruto } \\
& \text { - Tallo } \\
& \text { = Semilla } \\
& \text { - Raíz } \\
& \text { - Corteza } \\
& \text { = Estigma }
\end{aligned}
$$

Fig. 7. Parte utilizada de las plantas medicinales en Canelones.

Fig. 7. Used part of the medicinal plants in Canelones. 


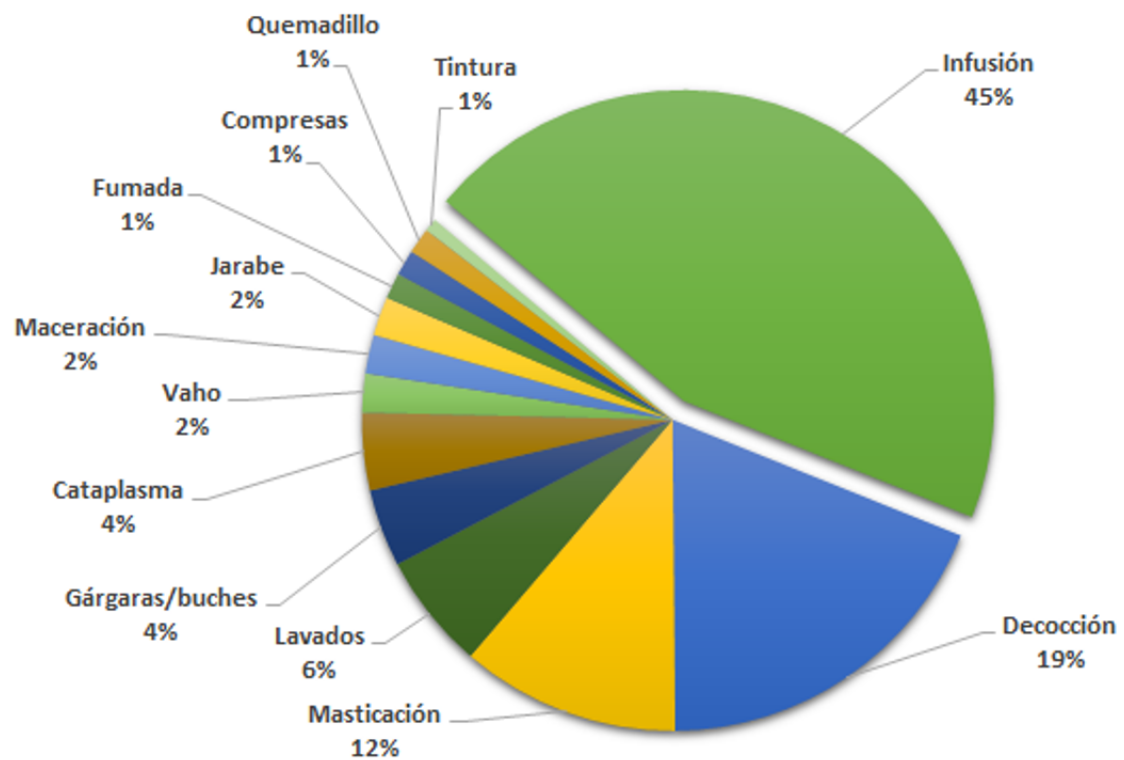

Fig. 8. Formas de consumo de las plantas medicinales en Tacuarembó.

Fig. 8. Forms of consumption of the medicinal plants in Tacuarembó.
E Infusión
Decocción
- Masticación
- Lavados
- Gárgaras/buches
- Cataplasma
vaho
- Mace ración
Jarabe
- Fumada
- Compresas
n Que madillo
- Tintura

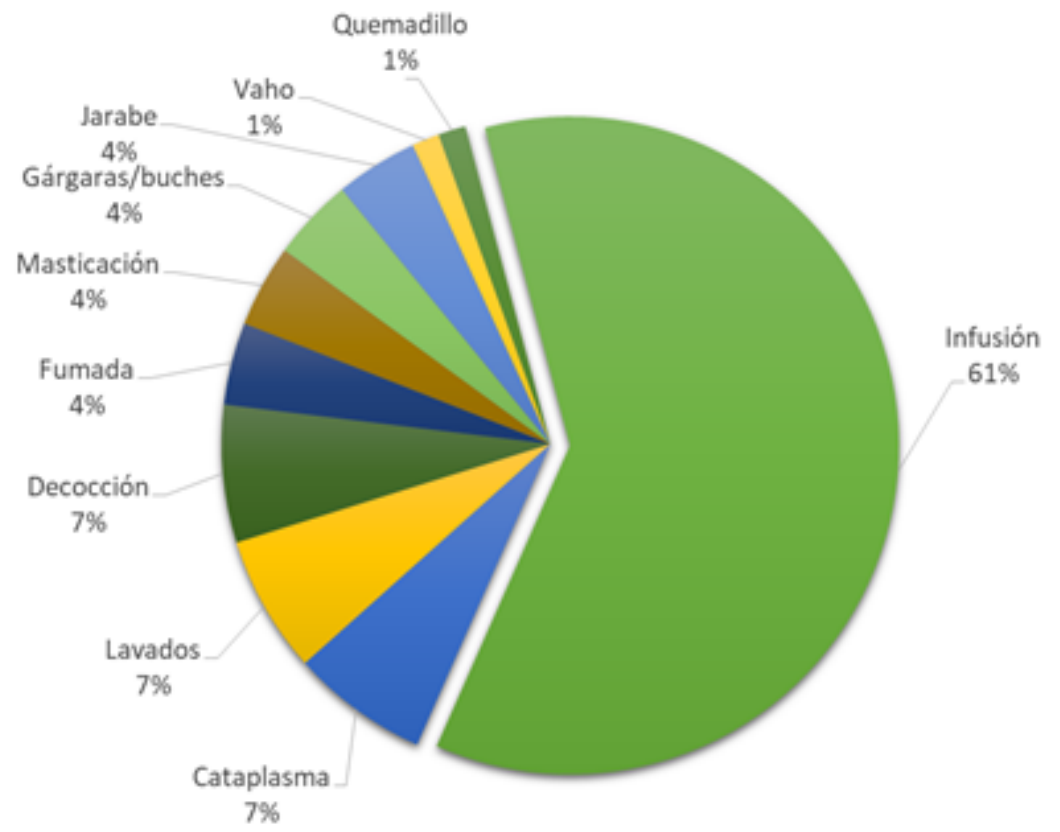

E Infusión

a Cataplasma

E Lavados

- Decocción

- Fumada

" Masticación

w Gárgaras/buches

a Jarabe

= Vaho

auemadillo

Fig. 9. Formas de consumo de las plantas medicinales en Canelones.

Fig. 9. Forms of consumption of the medicinal plants in Canelones. 


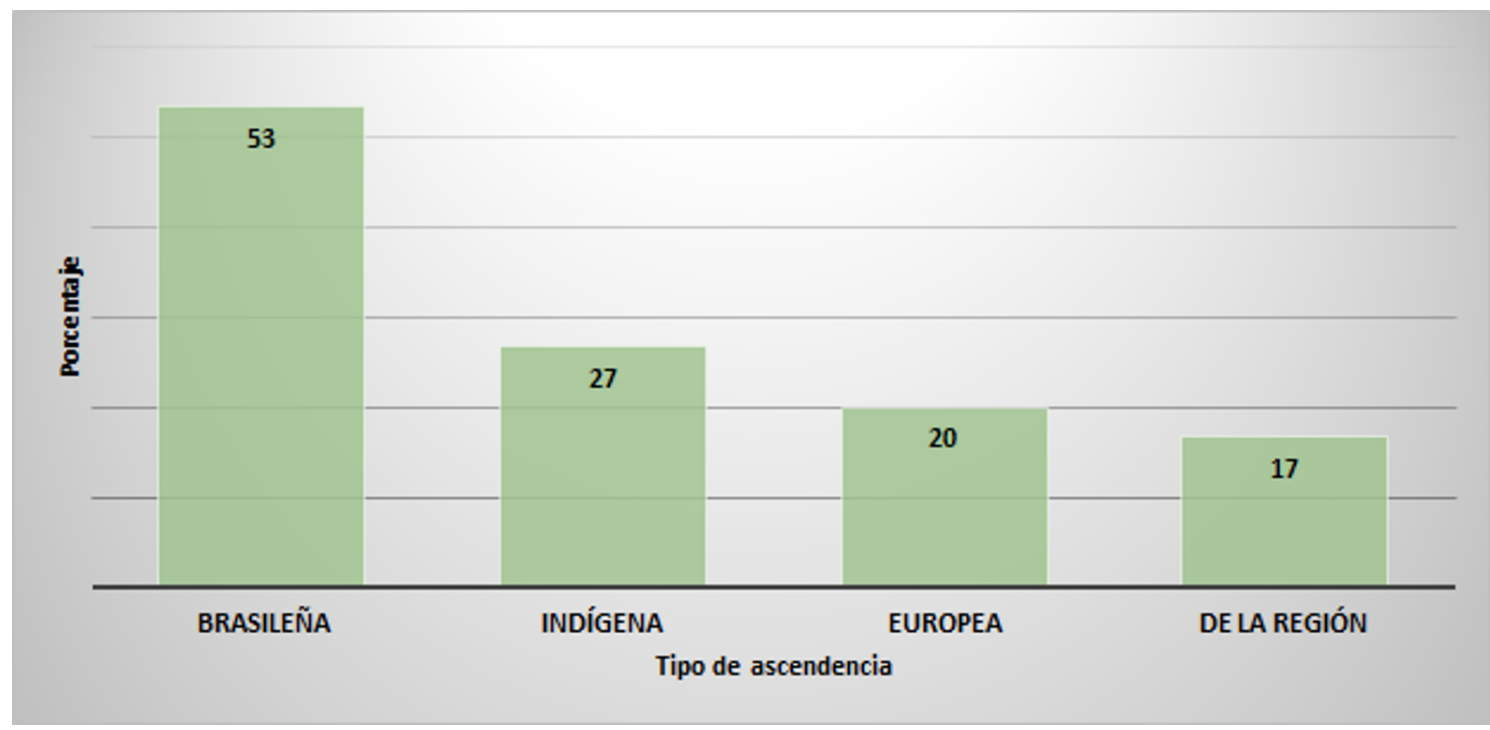

Fig. 10. Ascendencia de los entrevistados en el departamento de Tacuarembó.

Fig. 10. Ancestry of the interviewees in the department of Tacuarembó.

menta, mercurio, palma imperial, palo de jabón, pitanga, quina, sauce y yerba carnicera (Tabla 3).

Estas PM de uso indígena son utilizadas principalmente para tratar afecciones del Sistema Digestivo (33\%), Sistema Sensorial (21\%), Sistema Musculoesquelético (12\%) y Sistema Nervioso (10\%). Para las curaciones utilizan principalmente la hoja/parte aérea: $80 \%$ de los casos. Asimismo, 70\% de estas plantas tienen dos o más usos medicinales. Lo interesante de observar en estas $21 \mathrm{PM}$ de posible uso indígena, es que $54 \%$ de ellas se consumen a través de la masticación. Al indagar sobre la práctica de masticar plantas, varios de los entrevistados en Tacuarembó hacen referencia a que este hábito está vinculado a tradiciones indígenas.

"Si, hay plantas que se mastican que eran usadas por los indígenas, como ser la palma imperial. Si tiene una herida que no sana, usted la hierve, se lava bien lavadito y se cura. Después mastica un gajo de palma imperial y se pone en la herida. Esa que usaban los indios... el marrubio, es amargo, el marrubio se mastica (...) Ellos usaban todo lo que habia en el monte, casi todo era medicinal para los indígenas (Campesino indigena TIB)".
La práctica de masticar plantas junto a la saliva para curar ha sido vinculada a tradiciones indígenas a lo largo de la historia. Un claro ejemplo es la masticación de la planta del tabaco por indígenas norteamericanos y la hoja de coca por indígenas andinos. Así mismo, Vidart (2010: 54) hace referencia a que los charrúas "bebian sin bombilla, las tisanas de yerba mate (...) La yerba, que venía entreverada con el agua, se mascaba larga y golosamente: de tal modo se acentuaban sus notorias virtudes psicotónicas $y$ dinamógenas". También refiere a que los charrúas eran muy afectos a los cogollos de ceibo, cuyas mascaduras, arrojadas a lo largo del camino, indicaban la ruta seguida por los indios.

Por otra parte, establecer el origen biogeográfico de las PM utilizadas por los grupos indígenas de la región podría contribuir a reafirmar la información recabada. Aunque, tampoco podríamos precisar que una PM introducida no haya sido utilizada por estos grupos indígenas. Es de destacar que varias de las plantas mencionadas son euroasiáticas (como marrubio, melisa, menta) o especies nativas han recibido el nombre de la euroasiática, reflejando la pronta incorporación de la farmacopea introducida por los pueblos originarios, al igual que ocurre con la farmacopeas locales en otras zonas de Uruguay y países vecinos (Tabakian, 
Tabla 3. Plantas medicinales nombradas por los descendientes de los grupos indígenas como plantas medicinales utilizadas por los grupos nativos que habitaron la región norte del territorio uruguayo, forma de consumo de las plantas medicinales y el origen de las mismas.

Table 3. Medicinal plants named by the descendants of the indigenous groups as medicinal plants used by the natives that lived in the northern region of Uruguay, forms of consumption of the medicinal plants and the origin of them.

\begin{tabular}{|c|c|c|c|c|c|c|}
\hline \multicolumn{2}{|r|}{ Nombre Popular } & \multirow[t]{2}{*}{ Nombre Científico } & \multicolumn{3}{|c|}{ FORMAS DE CONSUMO } & \multirow{2}{*}{$\begin{array}{l}\text { ORIGEN } \\
\text { Nat./Int. }\end{array}$} \\
\hline & & & FC 1 & FC 2 & FC 3 & \\
\hline 1 & Árnica & $\begin{array}{l}\text { Acmella bellidioides (Sm.) R.K. } \\
\text { Jansen }\end{array}$ & Masticación & $\begin{array}{l}\text { gárgaras/ } \\
\text { buches }\end{array}$ & Cataplasma & Introducida \\
\hline 2 & Barba de indio & Tillandsia usneoides (L.) L. & Infusión & & & Nativa \\
\hline 3 & Calaguala & $\begin{array}{l}\text { Rumohra adiantiformis (G. Forst.) } \\
\text { Ching }\end{array}$ & Decocción & & & Nativa \\
\hline 4 & Carqueja & $\begin{array}{l}\text { Baccharis articulata (Lam.) Pers. I } \\
\text { B. trimera (Less.) DC. }\end{array}$ & Infusión & Masticación & & Nativa \\
\hline 5 & $\begin{array}{l}\text { Chapéu de } \\
\text { couro }\end{array}$ & $\begin{array}{l}\text { Echinodorus grandiflorus (Cham. \& } \\
\text { Schltdl.) Micheli }\end{array}$ & Infusión & & & Nativa \\
\hline 6 & Coronilla & Scutia buxifolia Reissek & Decocción & & & Nativa \\
\hline 7 & Guayabo & Acca sellowiana (O. Berg) Burret & Infusión & Fumada & & Nativa \\
\hline 8 & Guazatumba & Cestrum euanthes Schltdl. & Infusión & Maceración & & Nativa \\
\hline 9 & Llantén & Plantago major L. & Infusión & $\begin{array}{l}\text { gárgaras/ } \\
\text { buches }\end{array}$ & Masticación & Introducida \\
\hline 10 & Malvavisco & No identificada & Masticación & Lavados & & \\
\hline 11 & Marrubio & Marrubium vulgare $\mathrm{L}$. & Infusión & Masticación & Decocción & Introducida \\
\hline 12 & Mburucuyá & Passiflora caerulea L. & Infusión & & & Nativa \\
\hline 13 & Melisa / Toronjil & Melissa officinalis L. & Infusión & Masticación & & Introducida \\
\hline 14 & $\begin{array}{l}\text { Menta/Hierba } \\
\text { buena }\end{array}$ & $\begin{array}{l}\text { Mentha piperita L.I M. aquatica L./ } \\
\text { M. spicata L. }\end{array}$ & Infusión & Masticación & & Introducida \\
\hline 15 & Mercurio & Modiola caroliniana (L.) G. Don & Masticación & Cataplasma & & Nativa \\
\hline 16 & Palma imperial & Tanacetum vulgare $\mathrm{L}$. & Infusión & Masticación & Cataplasma & Introducida \\
\hline 17 & Palo de jabón & $\begin{array}{l}\text { Quillaja brasiliensis (A. St.-Hil. \& } \\
\text { Tul.) Mart. }\end{array}$ & Lavados & & & Nativa \\
\hline 18 & Pitanga & Eugenia uniflora L. & Infusión & Masticación & & Nativa \\
\hline 19 & Quina & Discaria americana Gillies \& Hook. & Infusión & Masticación & Decocción & Nativa \\
\hline 20 & Sauce & Salix humboldtiana Willd. & Decocción & & & Nativa \\
\hline 21 & Yerba carnicera & Conyza bonariensis (L.) Cronquist & Infusión & & & Nativa \\
\hline
\end{tabular}

2016; Castiñeira, 2017a; Stampella et al., 2018). De acuerdo con estas reflexiones, el origen de las PM mencionadas por los declarados descendientes de indígenas, como utilizadas por sus antepasados indígenas, representan $70 \%$ un origen nativo y $30 \%$ introducidas.

Para el caso del departamento de Canelones, $64 \%$ de los entrevistado tiene al menos un ascendente canario, $21 \%$ un ascendente español peninsular, $14,2 \%$ un ascendente vasco, $7,1 \%$ un ascendente italiano y $7,1 \%$ un ascendente indígena.
Los descendientes de canarios, $64 \%$, hicieron referencia a diez PM que eran utilizadas tradicionalmente por sus familias de origen: amapola, eneldo, granada, hinojo, malva, manzanilla, menta/levante, romero, ruda y tomillo (Tabla 4).

Estas plantas medicinales mencionadas por descendientes de canarios son utilizadas principalmente para tratar afecciones del sistema digestivo (37\%), sistema sensorial (21\%) y sistema nervioso (16\%). La principal forma de consumo de estas plantas es a 


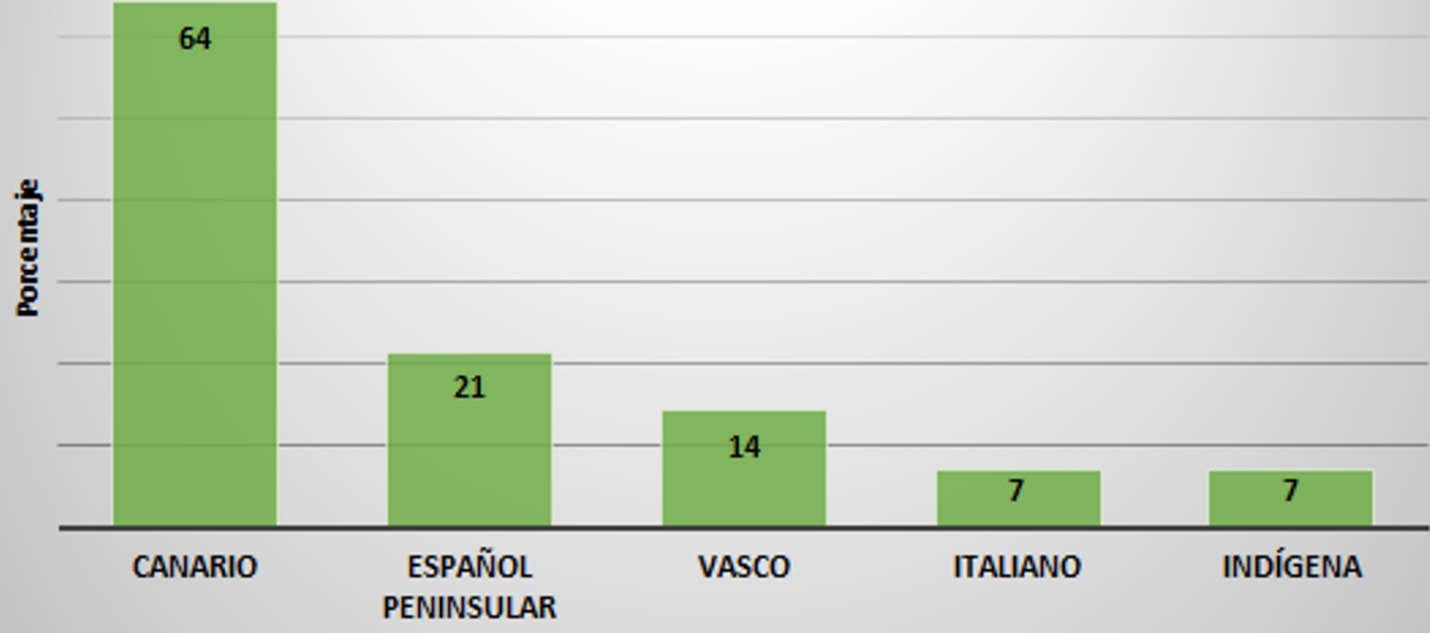

Tipo de ascendencia

Fig. 11. Ascendencia de los entrevistados en el departamento de Canelones.

Fig. 11: Ancestry of the interviewees in the department of Canelones.

través de la infusión (65\%). Para el caso de Canelones, $100 \%$ de las PM nombradas por los descendientes canarios, son introducidas y particularmente de origen europeo.

Determinar que una planta haya sido utilizada por un determinado grupo cultural resulta complejo, principalmente por el corte esperable en la transmisión de esta tradición etnobotánica como consecuencia de la exterminación de los grupos indígenas por un lado y por otro, un océano como corte en la transmisión europea. Si bien para confirmar este supuesto son necesarios trabajos futuros sistemáticos referidos a la transmisión del conocimiento en los sectores sociales participantes, los resultados del presente trabajo permiten reconocer la influencia de los diferentes grupos culturales que conforman hoy nuestra identidad en relación al aporte etnobotánico, en este caso los usos medicinales de las plantas. Esto estaría resignificando los beneficios que han tenido a lo largo de la historia el uso medicinal de las plantas en nuestra sociedad.

\section{Consideraciones finales}

Enlaactualidad, elusodeplantasmedicinales se ha incorporado como una práctica común, cumpliendo un rol fundamental en la salud de la sociedad uruguaya. En cada familia podemos encontrar al menos un integrante que consume plantas medicinales para aliviar diferentes afecciones (Tabakian, 2016). Así mismo, actores provenientes de variados ámbitos profesionales han estudiado los usos medicinales de las plantas, destacando la significancia social, cultural y económica de la incorporación de estos conocimientos al sistema de salud.

Las plantas medicinales aquí mencionadas tienen incidencia sobre más de un órgano del cuerpo humano, principalmente en los sistemas: digestivo, sensorial y respiratorio, siendo la hoja la parte más utilizada. La infusión es la forma de consumo predominante en las dos zonas de estudio.

El uso de ciertas plantas, según este trabajo, estaría relacionado a la ascendencia de los 
Tabla 4. Plantas medicinales utilizadas por el grupo cultural europeo, nombradas por los descendientes de españoles canarios, formas de uso de las plantas y el origen de las mismas.

Table 4. Medicinal plants used by the European cultural group, named by the descendants of Canarian Spaniards, forms of use of the plans and their origin.

\begin{tabular}{|c|c|c|c|c|c|c|}
\hline \multirow{2}{*}{\multicolumn{2}{|c|}{ Nombre Popular }} & \multirow{3}{*}{ Nombre Científico } & \multicolumn{3}{|c|}{ FORMAS DE CONSUMO } & \multirow{2}{*}{ ORIGEN } \\
\hline & & & \multirow{2}{*}{$\begin{array}{l}\text { FC } 1 \\
\text { Gárgaras/ } \\
\text { buches }\end{array}$} & & & \\
\hline 1 & Amapola & & & FC 2 & FC 3 & \\
\hline 2 & Eneldo & Anethum graveolens L. & Infusión & & & Introducida \\
\hline 3 & Granada & Punica granatum L. & Infusión & & & Introducida \\
\hline 4 & Hinojo & Foeniculum vulgare Mill. & Infusión & & & Introducida \\
\hline 5 & Malva & Malva sylvestris $\mathrm{L}$. & Infusión & Lavados & Decocción & Introducida \\
\hline 6 & Manzanilla & Matricaria chamomilla L. & Infusión & & & Introducida \\
\hline 7 & $\begin{array}{l}\text { Menta/ } \\
\text { Levante }\end{array}$ & $\begin{array}{l}\text { Mentha x piperita L. / M. } \\
\text { aquatica L. / Mentha sp. }\end{array}$ & Infusión & & & Introducida \\
\hline 8 & Romero & Rosmarinus officinalis L. & Infusión & Decocción & & Introducida \\
\hline 9 & Ruda & Ruta chalepensis L. & Infusión & & & Introducida \\
\hline 10 & Tomillo & Thymus vulgaris $\mathrm{L}$. & Infusión & Lavados & & Introducida \\
\hline
\end{tabular}

entrevistados. Sin embargo, se puede observar que localmente se menciona un quiebre generacional en la transmisión de estos saberes, que era el conocimiento que tenían los abuelos de los abuelos de hoy. La pérdida de esta valiosa información, complejiza en buena medida, determinar si un conocimiento vino en los barcos o fue transmitido en estas tierras. Con la medicalización se dejó de hablar de ciertos temas relacionados a la medicina popular. A su vez, según las personas mayores, los jóvenes no indagaban en su pasado y no intervenían en las conversaciones de los mayores, por tanto, no se preguntaba sobre el uso de PM, simplemente las usaban. Como proyección de este trabajo se considera importante confirmar estas percepciones a través de trabajos referidos a transmisión del conocimiento entre los distintos actores sociales participantes.

Si bien resulta complejo determinar el origen de estas prácticas, sí se puede conocer biogeográficamente el origen de las especies.
De esta manera, se puede concluir que $70 \%$ de las 21 PM nombradas por los descendientes indígenas, son de origen nativo, lo que estaría reivindicando el uso histórico de estas PM por los grupos que habitaron nuestra región.

Este origen nativo estaría apoyado también por la forma de consumo, con la notoria preponderancia de la práctica de masticación de plantas medicinales en Tacuarembó, sobre su vigencia en Canelones. El 54\% de estas plantas se utilizan mediante la masticación, que según los entrevistados, era habitual entre los indígenas del norte del territorio uruguayo. Así mismo, masticar plantas se vincula a tradiciones indígenas en otras zonas del continente. Para el caso de Canelones, 100\% de las 10 PM mencionadas como tradiciones de uso europeo, son introducidas. Por tanto, con esta investigación se pudo establecer una relación entre el origen de las PM mencionadas y sus prácticas, según los aportes poblacionales de ambos departamentos. Más allá de estos datos, lo significativo es que las 
PM forman parte de nuestro acervo cultural y lo que encontramos hoy es una mezcla de tradiciones etnobotánicas que conforman los actuales saberes locales sobre el uso medicinal de las plantas.

\section{Agradecimientos}

A las comunidades y pobladores que participaron de esta investigación y autorizaron su realización. A Marión Aguilera por compartir su sabiduría y conocimientos sobre las plantas medicinales. A las diferentes instituciones académicas que apoyaron y financiaron esta investigación: Facultad de Humanidades y Ciencias de la Educación (FHCE), Universidad de la República (UdelaR), Centro Universitario de Tacuarembó (CUT), Universidad de la República (UdelaR) y Comisión Sectorial de Investigación e Innovación (CSIC), Universidad de la República (UdelaR), en su programa de Iniciación a la Investigación. A mi orientadora del proyecto, Dra. Isabel Barreto, por su hospitalidad. A mi tutora de Doctorado, Dra. María Lelia Pochettino, por sus pertinentes comentarios e indicaciones. A los revisores que con sus atinadas sugerencias contribuyeron a mejorar este manuscrito.

\section{Bibliografía}

ACHKAR, M., DÍAZ, I., DOMÍNGUEZ, A. \& F. PESCE. 2016. Uruguay: naturaleza, sociedad y economía. Una visión desde la geografía. Ediciones de la Banda Oriental, Montevideo.

ACOSTA Y LARA, E. 1981. Un linaje Charrúa en Tacuarembó. Revista de la Facultad de Humanidades y Ciencias, serie Ciencias Antropológicas 1: 65-88.

ACOSTA Y LARA, E. 1989. La Guerra de los Charrúas en la Banda Oriental. Período Hispánico. LINARDI \& RISSO (eds.), Montevideo.

ARRILlAGA DE MAFFEI, B. 1969. Plantas Medicinales. Nuestra Tierra, vol. 31. Editorial Nuestra Tierra, Montevideo.

ARRILLAGA DE MAFFEI, B. 1997. Plantas usadas en medicina natural. Editorial Agropecuaria Hemisferio Sur, Montevideo.

ASOCIACIÓN URUGUAYA DE ANTROPOLOGÍA SOCIAL Y CULTURAL (AUAS). 2011. Revista
Trama 3, Dossier Etnobotánica. Disponible: https://tramarevista.files.wordpress.com/2011/08/ trama-3-1.pdf (Consulta: 20-X-2019).

BARRETO, I. 2008. Canarios de Ayer. La inmigración canaria en el Uruguay. Imprenta Gráfica Don Bosco, Montevideo.

BARRETO, I. \& C. CURBELO. 2009. Presencia indígena en el Uruguay: movilidad, estructura demográfica y conformación familiar al norte del Río Negro en el primer tercio del siglo XIX. Revista Digital Estudios Históricos 1. Disponible: https:// dialnet.unirioja.es/servlet/articulo?codigo $=3010853$ (Consulta: 20-X-2018).

BARRIOS PINTOS, A. 1981. Canelones. Su proyección en la Historia Nacional. Tomo II. Intendencia Municipal de Canelones, Uruguay.

BARRIOS PINTOS, A. 2000. Historia de los pueblos orientales. Tomos I y II. Academia Nacional de Letras, Montevideo.

BERCKOW, R., M. H. BEERS \& A. J. FLETCHER (eds.). 1997. Manual Merck de información médica general. Grupo editorial Océano, Barcelona.

BOUTON, R. J. [1958] 2014. La vida rural en el Uruguay. Ediciones Banda Oriental, Montevideo.

CABRERA PÉREZ, L. \& I. BARRETO. 2006. El ocaso del mundo indígena y las formas de integración a la sociedad urbana montevideana. Revista Tefros, 4(2). Disponible: http://www.hum.unrc.edu.ar/ojs/index. php/tefros/article/view/126 (Consulta: 20-X-2018).

CABRERA, Á. \& A. WILLINK. [1973] 1980. Biogeografía de América Latina. OEA, Programa Regional de Desarrollo Científico y Tecnológico. Serie de Biología. Monografía 13. Washington DC.

CASTIÑEIRA, E. 2017a. La etnobotánica en Uruguay y uma nueva herramienta para la investigación: La colección etnobotánica. Disponible: http:// www.auas.org.uy/trama/index.php/Trama/article/ view/142/80 (Consulta: 16-X-2018).

CASTIÑEIRA, E. 2017b. Etnobotánica aplicada a la conservación en el Parque Regional Quebradas del Norte, Rivera, Uruguay. Tesis Doctoral, Facultad de Ciencias Naturales y Museo. Universidad Nacional de La Plata, La Plata, Argentina.

CURBELO, C. 2009. Lengua y poder en San Borja del Yi (1833-1862). Ensayo para un análisis sociolingüístico. En Herencia indígena en el Uruguay, pp. 117-135. Linardi y Risso. Montevideo.

DEL PUERTO, O. 1969. Hierbas del Uruguay. Nuestra Tierra, vol. 19. Montevideo.

DEL PUERTO, O., P. DAVIES \& E. SEQUEIRA. 1990. Los nombres comunes de las plantas de la 
región platense. Departamento de Publicaciones y Ediciones de la Universidad de la República, Montevideo.

DI LISCIA, M. S. \& A. PRINA. 2002. Los saberes indígenas y la ciencia de la Ilustración. Revista Española de Antropología Americana 32: 295-319.

FURLONG, G. 1994. Los jesuitas y la cultura rioplatense. Editorial Biblos, Buenos Aires.

GONZÁLEZ, M., A. LOMBARDO \& A. VALLARINO. 1940. Plantas de la medicina vulgar del Uruguay: obra del más alto mérito científico, analítico y descriptivo, en la relación y aplicación de las plantas medicinales indígenas y exóticas cultivadas en el país. Editor Talleres Gráficos, Montevideo.

GUBER, R. 2011. La Etnografía: método, campo y reflexividad. Siglo XXI editores, Buenos Aires.

IBODA. 2019. Instituto de Botánica Darwinion. Flora del Conosur Catálogo de Plantas Vasculares. Disponible: http://www2.darwin.edu.ar/Proyectos/ FloraArgentina (Consulta: V-2019).

INE (INSTITUTO NACIONAL DE ESTADÍSTICAS). 2011. Departamento de Canelones. Disponible: http:// www5.ine.gub.uy/censos2011/resultadosfinales/ canelones.html (Consulta: 2-XI-2018).

INE (INSTITUTO NACIONAL DE ESTADÍSTICAS). 2011. Departamento de Tacuarembó. Disponible: http://www5.ine.gub.uy/censos2011/ resultadosfinales/tacuarembo.html. (Consulta: 2-XI-2018).

LARRAÑAGA, D. A. 1923. Escritos de Don Dámaso Antonio Larrañaga. Tomo II. Instituto Histórico y Geográfico (ed.). Imprenta Nacional, Montevideo. https://doi.org/10.5962/bhl.title.116606

LOMBARDO, A. [1946] 1964. Flora arbórea y arborescente del Uruguay. Consejo departamental de Montevideo, Dirección de Paseos Públicos, Montevideo.

LOMBARDO, A. 1984. Plantas medicinales de la flora indígena. Banco de Seguros del Estado. Almanaque 1985. Gráficos Barreiro y Ramos, Montevideo.

LOMBARDO, A. \& R. POU FERRARI. 1970. Sistemática. Editor Universidad de la República, Facultad de Agronomía, Montevideo.

MAÑÉ GARZÓN, F. 1996. Historia de la ciencia en el Uruguay. Tomo I. Del descubrimiento al fin de las Misiones Jesuíticas. Universidad de la República, Departamento de Publicaciones, Montevideo.

MAÑÉ GARZÓN, F. 2005. Historia de la ciencia en el Uruguay. Tomo III. Primera mitad del siglo XIX. Universidad de la República, Departamento de Publicaciones, Montevideo.
MARTIN, G. J. 1995. Etnobotánica: manual de métodos. Editorial Nordan-Comunidad, Montevideo.

MUÑOZ, J., P. ROSS \& P. CRACCO. 2007. Flora indígena del Uruguay, árboles y arbustos ornamentales. Editorial Hemisferio Sur, Montevideo.

PEREDA VALDÉS, I. 1943. Medicina popular y folklore mágico del Uruguay. Talleres Gráficos Galien, Montevideo.

SCHIAFFINO, R. 1927. Historia de la medicina en el Uruguay. Tomo I. Talleres de la Imprenta Nacional, Montevideo.

STAMPELLA, P., N. I. HILGERT \& M. L. POCHETTINO. 2018. Usos medicinales de los cítricos (Citrus L., Rutaceae) entre los criollos del sur de Misiones (Argentina). Gaia Scientia 12: 90-108. https://doi.org/10.22478/ufpb.1981$1268.2018 \mathrm{v} 12 \mathrm{n} 1.32838$

TABAKIAN, G. 2012. Plantas medicinales: transmisión de saberes populares. Disponible: https://www. youtube. $\mathrm{com} /$ watch? $\mathrm{v}=$ Z4IQZyDy3iU\&t $=1 \mathrm{~s}$. (Consulta: 20-I-2019).

TABAKIAN, G. 2015. La ruta de las plantas medicinales por el sudeste asiático. En ROMERO GORSKI, S. (ed.), Anuario de Antropología Social y Cultural en Uruguay, pp. 243-259. Editorial Nordan-Comunidad. Instituto de Antropología, FHUCE, Montevideo.

TABAKIAN, G. 2016. Documental etnográfico: Etnobotánica de plantas medicinales en el departamento de Tacuarembó, Uruguay. Disponible: https://www.youtube.com/ watch? $=$ =tQfodxVpWuA (Consulta: 20-I-2019).

TABAKIAN, G. 2017a. Etnomedicina y Etnobotánica en el departamento de Tacuarembó, Uruguay. Rev. urug. Antropología y Etnografía, Montevideo , v. 2, n. 2, p. 61-72, dic. 2017 . Recuperado de $<$ http://www.scielo.edu.uy/scielo.php?script $=$ sci arttext\&pid=S2393-68862017000200061\&lng=es\& nrm=iso $>$ (Consulta: 16-X-2018).

TABAKIAN, G. 2017b. Plantas medicinales vinculadas a tradiciones indígenas en el norte uruguayo. Revista Trama. Montevideo, v.8, p 44-56 Recuperado de: http://www.auas.org.uy/ trama/index.php/Trama/article/download/133/86 (Consulta: 16-X-2018).

TAYLOR, S. J. \& R. BOGDAN. 1992. Introducción a los métodos cualitativos en investigación. La búsqueda de los significados. Ed. Paidós, España.

THE PLANT LIST. 2013. Version 1.1. Disponible: http://www.theplantlist.org/ (Consulta: IV-2019).

VIDART, D. 1969. Tipos humanos del campo y la ciudad. Colección Nuestra Tierra, vol. 12. Montevideo. 
VIDART, D. 2010. El mundo de los charrúas. Ediciones de la Banda Oriental, Montevideo.

VIDART, D. \& R. PI HUGARTE. 1969. El legado de los inmigrantes II. Colección Nuestra Tierra, vol. 39. Montevideo.
VERA DE FLACHS, M. \& C. PAGE. 2010. Textos clásicos de medicina en la Botica Jesuítica del Paraguay. Revista CIAN de Historia de las Universidades 13(1). Disponible: https://e-revistas.uc3m.es/index. php/CIAN/article/view/4 (Consulta: 16-X-2018). 